\title{
1 Effect of Strain Rate and Strain Softening on Embedment Depth of a
}

\section{Torpedo Anchor in Clay}

3

4

\section{Y. Kim ${ }^{1}$, M. S. Hossain ${ }^{2}$ and D. Wang ${ }^{3}$}

5

$6 \quad{ }^{1}$ Research Associate (PhD), Centre for Offshore Foundation Systems (COFS), The University

7 of Western Australia, Tel: $+61 \quad 8 \quad 6488$ 4316, Fax: +61 86488 1044, Email:

8 youngho.kim@uwa.edu.au

$9 \quad{ }^{2}$ Corresponding Author, Associate Professor (BEng, MEng, PhD, MIEAust), ARC DECRA

10 Fellow, Centre for Offshore Foundation Systems (COFS), The University of Western 11 Australia, 35 Stirling highway, Crawley, WA 6009, Tel: +61 86488 7358, Fax: +61 86488

12 1044, Email: muhammad.hossain@uwa.edu.au

$13{ }^{3}$ Associate Professor (PhD), Centre for Offshore Foundation Systems (COFS), The University

14 of Western Australia, Tel: +61 86488 3447, Fax: +61 86488 1044, Email:

15 dong.wang@uwa.edu.au

17 - Number of Words: 5462 (text only)

18 - Number of Tables: 01

19 - Number of Figures: 12 


\section{Torpedo Anchor in Clay}

Abstract: Torpedo anchors (of diameter $\sim 1 \mathrm{~m}$ ) are released from a height of 50 100 $\mathrm{m}$ from the seabed, achieving velocities up to $35 \mathrm{~m} / \mathrm{s}$ at impacting the sediment. The strain rates induced in the surrounding soil by this dynamic installation is therefore significantly higher than those associated with installation of other offshore foundations and anchoring systems. The high strain rates enhance the mobilised undrained shear strength compared to that measured by in-situ penetrometer or laboratory tests. This paper reports the results from dynamic installation of a torpedo anchor in strain softening, rate dependent soft clays, quantifying the effects relative to results for ideal Tresca material. The three-dimensional dynamic large deformation finite element (LDFE) analyses were carried out using the coupled Eulerian-Lagrangian approach. The simple elastic-perfectly plastic Tresca soil model was modified to allow strain softening and strain rate dependency of the shear strength. Parametric analyses were undertaken varying the strain rate parameter, the sensitivity and ductility of the soil, and the soil undrained shear strength. Overall, embedment depth for rate dependent, strain softening clays lay below that for ideal Tresca material. Increased strain rate dependency of the soil led to marked reduction in embedment depth, only partly compensated by brittleness. Key results have been presented in the form of design charts, fitted by simple expressions to estimate the embedment depth of a torpedo anchor.

KEYWORDS: torpedo anchors; clay sensitivity; strain rate dependency; dynamic installation; embedment depth; numerical modelling 
$43 \quad \mathrm{~A}_{\mathrm{A}} \quad$ anchor shaft cross-section area

$44 \quad \mathrm{AbF}_{b \mathrm{f}} \quad$ fins projected area

$45 \quad A_{p} \quad$ anchor shaft and fins projected area

$46 \quad \mathrm{~A}_{\mathrm{s}} \quad$ total surface area of anchor

$47 \quad$ A $_{\mathrm{sA}}$ embedded anchor shaft surface area

$48 \quad \mathrm{~A}_{\mathrm{sF}} \quad$ embedded fin surface area

$49 \mathrm{C}_{\mathrm{d}} \quad$ drag coefficient

$50 \quad \mathrm{D}_{\mathrm{A}} \quad$ anchor shaft diameter

$51 \quad D_{p} \quad$ anchor projected area equivalent diameter (including fins)

$52 \mathrm{~d}_{\mathrm{e}, \mathrm{t}} \quad$ installed anchor tip embedment depth

$53 \quad \mathrm{~d}_{\mathrm{t}} \quad$ anchor tip penetration depth

$54 \quad E_{\text {total }}$ total energy during anchor penetration

$55 \quad \mathrm{Fb}_{\mathrm{b}} \quad$ end bearing resistance

$56 \quad \mathrm{~F}_{\mathrm{b}, \mathrm{bA}}$ end bearing resistance at base of anchor shaft

$57 \quad \mathrm{~F}_{\mathrm{b}, \mathrm{bF}} \quad$ end bearing resistance at base of anchor fins

$58 \quad \mathrm{~F}_{\mathrm{d}} \quad$ inertial drag resistance

$59 \quad \mathrm{~F}_{\mathrm{f}} \quad$ frictional resistance 
$60 \quad \mathrm{~F}_{\mathrm{fA}} \quad$ frictional resistance along shaft

$61 \quad \mathrm{~F}_{\mathrm{fF}} \quad$ frictional resistance along fins

$62 \mathrm{~F}_{\gamma} \quad$ buoyant weight of soil displaced by anchor (calculated using effective unit weight of 63 soil)

$64 \mathrm{~g}$ earth's gravitational acceleration

$65 \mathrm{k} \quad$ shear strength gradient with depth

66 LA anchor shaft length

$67 \quad L_{F} \quad$ fin length

$68 \mathrm{~L}_{\mathrm{T}} \quad$ anchor shaft tip length

69 m anchor mass

$70 \quad \mathrm{~m}^{\prime} \quad$ anchor effective mass

$71 \mathrm{~N}_{\mathrm{c}, \mathrm{bA}}$ anchor tip bearing capacity factor

$72 \quad \mathrm{~N}_{\mathrm{c}, \mathrm{bF}}$ fin bearing capacity factor

$73 \mathrm{n} \quad$ factor relating operative shear strain rate to normalised velocity

$74 \quad R_{a} \quad$ average strain rate coefficient for embedment prediction

$75 \mathrm{R}_{\mathrm{b}} \quad$ average strain rate coefficient for energy method

$76 \mathrm{R}_{\mathrm{f} 1} \quad$ factor related to effect of strain rate and softening for end bearing resistance

$77 \quad \mathrm{R}_{\mathrm{f} 2}$ factor related to effect of strain rate and softening for frictional resistance 
$78 \mathrm{~S}_{\mathrm{t}} \quad$ soil sensitivity

79 Su undrained shear strength

80 Su,bA undrained shear strength at bottom of anchor shaft

$81 \mathrm{Su}, \mathrm{bF} \quad$ undrained shear strength at bottom of fins

$82 \mathrm{Su}, \mathrm{ref}$ reference undrained shear strength

$83 \quad \mathrm{su}, \mathrm{sA}$ average undrained shear strength over embedded length of shaft

$84 \quad$ Su,sF average undrained shear strength over embedded length of fin

85 Su,tip undrained shear strength at anchor tip level

86 Sum undisturbed soil strength at mudline

87 Sum,ref reference undisturbed soil strength at mudline

$88 \mathrm{t} \quad$ time after anchor tip impacting seabed

$89 t_{\mathrm{F}} \quad$ fin thickness

$90 \mathrm{~V} \quad$ anchor penetration velocity

$91 \quad \mathrm{~V}_{\mathrm{i}} \quad$ anchor impact velocity

92 WF fin width

$93 \mathrm{~W}_{\mathrm{d}}$ anchor dry weight

$94 \quad \mathrm{~W}_{\mathrm{s}} \quad$ anchor submerged weight in water

$95 \quad \mathrm{Z} \quad$ depth below soil surface 
$96 \alpha \quad$ interface friction ratio

$97 \quad \beta \quad$ shear-thinning index

$98 \quad \beta_{\text {tip }} \quad$ anchor tip angle

$99 \Delta \mathrm{t} \quad$ incremental time

$100 \Delta \varepsilon_{1} \quad$ cumulative major principal strain

$101 \Delta \varepsilon_{3} \quad$ cumulative minor principal strain

$102 \delta_{\text {rem }}$ fully remoulded ratio

$103 \gamma^{\prime} \quad$ effective unit weight of soil

$104 \dot{\gamma}_{\text {ref }} \quad$ reference shear strain rate

$105 \quad \dot{\gamma} \quad$ shear strain rate

$106 \eta \quad$ viscous property

$107 \mu_{\mathrm{c}} \quad$ Coulomb friction coefficient

$108 \theta_{0} \quad$ pullout angle at mudline

$109 \theta_{\mathrm{a}} \quad$ pullout angle at padeye

$110 \quad \rho_{\mathrm{s}} \quad$ submerged soil density

$111 \tau_{\max } \quad$ limiting shear strength at soil-anchor interface

$112 \xi \quad$ cumulative plastic shear strain 
$113 \xi_{\mathrm{a}}$ average cumulative plastic shear strain for embedment prediction

$114 \xi_{\mathrm{b}} \quad$ average cumulative plastic shear strain for energy method

$115 \xi_{95}$ cumulative plastic shear strain required for $95 \%$ remoulding 
117 Dynamically installed anchors (DIAs) are the most recent generation of anchoring systems for

118 mooring floating facilities in deep waters. They have been identified as one of the most cost-

119 effective and promising concepts for future oil and gas development in the emerging frontiers.

120 The anchor is released from a designed height above the seabed. This allows the anchor to

121 gain velocity as it falls freely through the water column before impacting and embedding

122 within the sediments.

123 The most commonly used DIAs are rocket-shaped, referred to as torpedo anchors, typically

$124 \quad 12 \sim 17 \mathrm{~m}$ long and $0.8 \sim 1.2 \mathrm{~m}$ in diameter, with a dry weight $\left(\mathrm{W}_{\mathrm{d}}\right)$ of $230 \sim 1150 \mathrm{kN}$, and may

125 feature up to 4 fins at the trailing edge (see Figure 1; Brandão et al. 2006). They are released

126 from a height of 50 100 m from the seabed, achieving velocities up to $35 \mathrm{~m} / \mathrm{s}$. Challenges

127 associated with dynamically penetrating anchors include prediction of the anchor embedment

128 depth and the subsequent capacity. The former is complicated by the very high strain rate

129 (exceeding $25 \mathrm{~s}^{-1}$ ) at the soil anchor interface, resulting from the high penetration velocities.

130 There is general agreement that the undrained strength increases with increasing shear strain

131 rate (e.g. Biscontin and Pestana 2001; DeGroot et al. 2007; Lunne and Andersen 2007;

132 Dejong et al. 2012). Furthermore, natural soils also undergo softening as they are sheared and

133 remoulded, with typical sensitivity values ranging from 2 to 5 for marine clays and 2 to 2.8

134 for reconstituted kaolin clay used widely in centrifuge tests (Kvalstad et al. 2001; Andersen

135 and Jostad 2004; Randolph 2004; Menzies and Roper 2008; Lunne et al. 2011; Gaudin et al.

136 2014).

137 The paper is a continuation of one that presents results from a parametric study: exploring the

138 relevant range of parameters in terms of anchor length; diameter; tip angle; number, width

139 and length of fins; impact velocity and soil undrained shear strength (Kim et al. 2015). In that 
140 paper, large deformation finite element (LDFE) analyses were carried out, accounting for the

141 effect of strain rate and softening, but corresponding to a particular (kaolin) clay. In this

142 study, the reverse was undertaken i.e. a typical torpedo anchor geometry and impact velocity

143 were considered and parametric analyses were performed varying the soil sensitivity,

144 brittleness and strain rate properties. The influence of these parameters on the proposed

145 design expressions for anchor embedment depth was quantified. Analyses were also

146 conducted simulating ideal Tresca, i.e. rate independent and non-softening, material for

147 comparison.

148 Extensive background information to installation of torpedo anchors can be found in Hossain 149 et al. (2014, 2015) and Kim et al. (2015), which are not repeated here. For convenience, 150 Figures 1 and 2 from Kim et al. (2015) are used here, showing a typical anchor geometry 151 defining the nomenclature adopted for the problem and typical mesh details respectively.

\section{Numerical Analysis}

\section{Geometry and Parameters}

155 This study has considered a torpedo anchor, consisting of a circular shaft attached with 4 156 rectangular fins, penetrating dynamically into a soft non-homogeneous clay deposit as

157 illustrated schematically in Figure 1, where the mudline strength sum, increases linearly with

158 depth $\mathrm{z}$, with a gradient $\mathrm{k}$. The soil average effective unit weight is $\gamma^{\prime}$. The anchor shaft 159 diameter is $\mathrm{D}_{\mathrm{A}}$ of $1.07 \mathrm{~m}$, shaft length $\mathrm{L}_{\mathrm{A}}$ of $17 \mathrm{~m}$ (including tip length, $\mathrm{L}_{\mathrm{T}}$ ), fin length $\mathrm{L}_{\mathrm{F}}$ of $16010 \mathrm{~m}\left(=\mathrm{LF}_{1}+\mathrm{L}_{\mathrm{F} 2}+\mathrm{LF}_{\mathrm{F} 3}\right)$ and fin width $\mathrm{WF}_{\mathrm{F}}$ of $0.9 \mathrm{~m}$. Analyses were undertaken for anchors 161 with a $30^{\circ}$ conical tip $\left(\beta_{\text {tip }}=30^{\circ}\right)$. The shape was chosen similar to the $\mathrm{T}-98$ anchor in the 162 field, as illustrated by Medeiros (2002), de Araujo et al. (2004) and Brandão et al. (2006). 


\section{Analysis Details}

164

165

166

167

3D LDFE analyses were carried out using the coupled Eulerian-Lagrangian (CEL) approach in the commercial package ABAQUS/Explicit (Dassault 2011). To reduce the computational effort, the anchor dynamic installation was modelled from the soil surface, with a given velocity $\mathrm{Vi}$.

Considering the symmetry of the problem, only a quarter anchor and soil were modelled. The radius and height of the soil domain were $40 \mathrm{D}_{\mathrm{A}}\left(\sim 32 \mathrm{D}_{\mathrm{p}}\right.$ for 4 -fin anchor $)$ and $\sim 8 \mathrm{~L}_{\mathrm{A}}$, respectively, to ensure that the soil extensions are sufficiently large to avoid boundary effect in dynamic analyses. A very fine soil mesh was necessary to capture the anchor-soil contact accurately. Based on the mesh convergence studies from Kim et al. (2015), the typical soil element size along the trajectory of the anchor is adopted as $0.019 \mathrm{D}_{\mathrm{A}}$. A typical mesh is shown in Figure 2. The mesh comprised 8-noded linear brick elements with reduced integration, and a fine mesh zone is generated to accommodate the anchor trajectory during the entire installation. A $5 \mathrm{~m}$ thick void (i.e. material free) layer was set above the soil surface (see Figure 2c), allowing the soil to heave by flowing into the empty Eulerian elements during the penetration process. The anchor was simplified as a rigid body.

The installation of torpedo anchors in clay is completed under nearly undrained conditions. The soil was thus modelled as an elasto-perfectly plastic material obeying a Tresca yield criterion, but extended as described later to capture strain rate and strain softening effects. A user subroutine of Abaqus was coded to track the evolving soil undrained shear strength profile. The elastic behaviour was defined by a Poisson's ratio of 0.49 and Young's modulus of $500 \mathrm{~s}_{\mathrm{u}}$ throughout the soil profile (where $\mathrm{s}_{\mathrm{u}}$ represents the current undrained strength of clay). A uniform submerged unit weight of $6 \mathrm{kN} / \mathrm{m}^{3}$ was adopted over the soil depth, representing a typical average value for field conditions. 
187 The soil-anchor interface was modelled as frictional contact, using a general contact algorithm 188 and specifying a Coulomb friction law together with a limiting shear stress $\left(\tau_{\max }\right)$ along the 189 anchor-soil interface. The Coulomb friction coefficient was deliberated set to a high value of

$190 \mu_{\mathrm{C}}=50$, in order to allow the value of $\tau_{\max }$ to govern failure. Within the CEL, the value of the 191 limiting interface friction must be set prior to the analysis, before the value of the 'adjacent' 192 soil strength is known. To overcome this difficulty, for each case, the limiting interface 193 friction was determined by: (1) simulating anchor penetration with frictionless contact; (2)

194 obtaining the final anchor tip penetration depth and calculating Su,ref at that depth; and (3) 195 setting $\tau_{\max }$ equal to an interface friction ratio, $\alpha$, times the calculated $\mathrm{su,ref}$ at the final tip 196 depth (from frictionless contact), with $\alpha$ taken as the inverse soil sensitivity, $1 / \mathrm{S}_{\mathrm{S}}$. Due to the 197 limitation of the current CEL approach, $\tau_{\max }$ is a constant value along the anchor surfaces 198 during the entire calculation. At shallow depth, where $\tau_{\max }$ may exceed the rate dependent 199 shear strength of the adjacent soil, failure may occur at the nearest integration points, rather 200 than at the interface. The contact interface is created between Lagrangian mesh and Eulerian 201 material, and automatically computed and tracked during the analysis.

\section{Incorporation of Combined Effects of Strain Rate and Strain Softening}

203 For this high velocity problem, a Herschel-Bulkley rheological model (H-B, Herschel and 204 Bulkley 1926) is considered to be superior to the semi-logarithmic rate law for simulating 205 geotechnical problems involving high strain rate (Raie and Tassoulas 2009; Zhu and 206 Randolph 2011; Boukpeti et al. 2012). Except for the rate dependency, the softening induced 207 by accumulated plastic strains is involved. The undrained shear strength at individual Gauss 208 points was modified immediately after each step, according to the average rate of maximum 209 shear strain in the previous time step and the current accumulated absolute plastic shear strain, 210 as 
$211 \mathrm{~s}_{\mathrm{u}}=\left[1+\eta\left(\frac{\dot{\gamma}}{\dot{\gamma}_{\text {ref }}}\right)^{\beta}\right]\left[\delta_{\text {rem }}+\left(1-\delta_{\text {rem }}\right) \mathrm{e}^{-3 \xi / \xi_{95}}\right] \frac{\mathrm{s}_{\mathrm{u}, \mathrm{ref}}}{(1+\eta)}$

212 where $\mathrm{su,ref}$ is the shear strength at the reference shear strain rate of $\dot{\gamma}_{\text {ref }}$. The first bracketed

213 term of Equation 1 augments the strength according to the operative shear strain rate, $\dot{\gamma}$,

214 relative to a reference value, $\dot{\gamma}_{\text {ref }}$, which is typically around $10^{-5} \mathrm{~s}^{-1}$ for laboratory element

215 tests and up to $\sim 0.5 \mathrm{~s}^{-1}$ for field penetrometer testing (although in the latter case the high strain

216 rate is partly compensated for by strain softening). Ideally, the shear strength should be

217 deduced from a reference strain rate, $\dot{\gamma}_{\text {ref }}$, that is relatively close (within 2 to 3 orders of

218 magnitude) to that relevant for the application. The parameter $\eta$ is a viscous property and $\beta$

219 the shear-thinning index. Boukpeti et al. (2012) carried out a series of undrained shear

220 strength measurements on two different (kaolin and Burswood) clays from fall cone tests,

221 vane shear, T-bar and ball penetrometer tests. They reported typical values of $\eta$ and $\beta$ in the

222 range of $0.1 \sim 2.0$ and $0.05 \sim 0.15$, respectively, using $\dot{\gamma}_{\text {ref }}=0.06 \mathrm{~s}^{-1}$. O'Loughlin et al.

223 (2013) and Chow et al. (2014) used $\dot{\gamma}_{\text {ref }}=0.17 \mathrm{~s}^{-1}$ and $0.1 \mathrm{~s}^{-1}$ for analysing centrifuge test

224 data form installation of torpedo anchors and a dynamic cone penetrometer, respectively, in

225 kaolin clay. Based on these, here a value of $\dot{\gamma}_{\text {ref }}=0.1 \mathrm{~s}^{-1}$ was adopted, and rate parameters

226 were varied as $\eta=0.1 \sim 1.5$ and $\beta=0.05 \sim 0.2$. The shear strain rate, $\dot{\gamma}$, within the soil was

227 evaluated according to

$228 \quad \dot{\gamma}=\frac{\Delta \varepsilon_{1}-\Delta \varepsilon_{3}}{\Delta \mathrm{t}}$

229 where $\Delta \varepsilon_{1}$ and $\Delta \varepsilon_{3}$ are the cumulative major and minor principal strains, respectively, over the 230 incremental time, $\Delta \mathrm{t}$. 
The second part of Equation 1 models the degradation of strength according to an exponential

232 function of cumulative plastic shear strain, $\xi$, from the intact condition to a fully remoulded 233 ratio, $\delta_{\text {rem }}$ (the inverse of the sensitivity, $\mathrm{S}_{\mathrm{t}}$ ). The relative ductility is controlled by the 234 parameter, $\xi_{95}$, which represents the cumulative shear strain required for $95 \%$ remoulding. 235 Typical values of $\xi_{95}$ have been estimated as around $10 \sim 30$ (i.e. 1,000 3,000\% shear strain; 236 Randolph 2004; Zhou and Randolph 2009).

237 The range of parameters considered is summarised in Table 1, encompassing most cases of 238 practical interest. The base-case parameters were taken as $\dot{\gamma}_{\text {ref }}=0.1 \mathrm{~s}^{-1}$ and $\mathrm{vi}_{\mathrm{i}}=20 \mathrm{~m} / \mathrm{s}$.

\section{Effects Evaluation and Discussion}

241 Details of failure mechanisms and penetration trends associated with different torpedo anchor 242 configurations have been documented by Kim et al. (2015). Results in the following sections 243 will focus mainly on the effect of parameters pertinent to strain rate and strain softening 244 leading to development of quantitative design charts in relation to the results for ideal Tresca 245 material.

Effect on Failure Mechanisms

247 Figure 3a shows the anchor penetration depth, as a function of time, in a soil with su,ref $=5+$ $2482 \mathrm{z} \mathrm{kPa}\left(\mathrm{kD}_{\mathrm{A}} / \mathrm{Sum}\right.$, ref $=0.43$, sum,ref $/ \gamma^{\prime} \mathrm{D}_{\mathrm{A}}=0.78$; Table 1$)$. Three profiles correspond to (i) the 249 ideal rate independent $(\eta=0)$, non-softening soil $\left(\delta_{\text {rem }}=1\right)$, (ii) rate dependent, strain 250 softening soil $\left(\xi_{95}=20, \eta=1.5, \beta=0.2, \dot{\gamma}_{\text {ref }}=0.1 \mathrm{~s}^{-1}, \delta_{\text {rem }}=0.33\right)$, and (iii) rate dependent, 251 non-softening soil $\left(\xi_{95}=20, \eta=1.5, \beta=0.2, \dot{\gamma}_{\text {ref }}=0.1 \mathrm{~s}^{-1}, \delta_{\text {rem }}=1\right)$. The soil failure 252 mechanisms and velocity profiles corresponding to (i) and (ii) are shown in Figure 3b. Clearly, 
the anchor penetration profile and corresponding soil failure mechanisms can be divided into

254 two stages. Stage 1 corresponds to shallow penetration where the anchor accelerates although

255 it advances into the soil. The soil resistance was less than the submerged weight of the anchor.

256 The combined effect of various soil parameters in terms of rate dependency and strain 257 softening $\left(\eta, \beta, \delta_{\text {rem, }} \xi_{95}\right)$ is minimal on the depth of stage 1 . This is, at least partly, due to 258 separation of the shaft and fins from the adjacent soils at the sharp transition zones between 259 the anchor tip and shaft and shaft and fins (Figure 3c), and corresponding reduction in 260 frictional resistances.

261 In Stage 2, as soil strength increases with depth, the anchor penetration resistance (frictional 262 plus end bearing) overcome the submerged weight, negated by the buoyancy force, of the 263 anchor and the anchor decelerates. This leads to a reduction of the extent of soil deformation 264 at the tip and the base of the anchor shaft and fins (e.g. at $t=0.9 \mathrm{~s}$; see Figure $3 \mathrm{~b}$ ). Finally, the 265 soil movement nearly diminishes with the anchor achieving its final embedment depth i.e. 266 coming to the rest. The penetration velocity for rate dependent and strength-softened soil 267 decreases faster compared to that for ideal Tresca material, leading to an increasingly lower 268 penetration depth. This is caused by the enhancement of the local shear strength (cross269 coupling between the effects of strain rate and strain softening) and hence frictional and 270 bearing resistances. The final embedment depth for the rate dependent, strain softening soil is 271 lower than that for ideal Tresca material. This also confirms that rate dependency and 272 softening have influence on deep penetration.

\section{Effect on Embedment Depth}

274 The embedment depth of a torpedo anchor on non-homogeneous clays is affected by a 275 number of factors: (a) the strain rate parameters ( $\eta$ and $\beta$ ); (b) the strain softening parameter $276\left(\xi_{95}\right)$; (c) the remoulded ratio $\left(\delta_{\text {rem }}\right)$ and the soil sensitivity $\left(\mathrm{S}_{\mathrm{t}}\right)$; $(\mathrm{d})$ the reference strain rate 
and $\left(\dot{\gamma}_{\text {ref }}\right)$; (e) the impact velocity $\left(\mathrm{v}_{\mathrm{i}}\right)$; and (f) the clay strength $\left(\mathrm{s}_{\mathrm{u}, \mathrm{ref}}\right)$. The results are

278 discussed below in relation to these various factors. In all the embedment depth curves, the 279 anchor penetration is plotted relative to the depth of the anchor tip below the original ground 280 surface. The computational parameters were adopted in the CEL analyses (e.g. the soil 281 element size along the trajectory of the anchor of $0.019 \mathrm{D}_{\mathrm{A}}$ ) based on the results of the 282 convergence studies reported by Kim et al. (2015).

\section{Effect of Rate Parameters ( $\eta$ and $\beta$ )}

The rate parameters, $\eta$ and $\beta$, were varied between 0 and 1.5 and 0.05 and 0.2 respectively.

285 The effect on the embedment depth for upper $(\eta=1.5$ and $\beta=0.2)$, intermediate 286 $(\eta=1.0$ and $\beta=0.1)$ and lower bound $(\eta=0.1$ and $\beta=0.05)$ combinations of rate 287 parameters are plotted in Figure 4 for ductility parameter of $\xi_{95}=20$ (all the results will be discussed later). The result for ideal rate independent, non-softening soil is also included for comparison. Overall, the embedment depth reduces with increasing viscous property ( $\eta)$ and shear-thinning index $(\beta)$, indicating the effect of enhancing undrained shear strength.

Interestingly, it is apparent that for high rate dependency, $\eta=1.5$ and $\beta=0.2$, the effect of strain softening is small and the curve lies above the one for ideal Tresca material. However, as the rate dependency becomes lower, the influence of softening becomes more marked, and the curve lies below the one for ideal Tresca material. For instance, for $\mathrm{vi}_{\mathrm{i}}=20 \mathrm{~m} / \mathrm{s}, \xi_{95}=20$ and $\delta_{\text {rem }}=0.33$ (see Figure 4), the highest embedment depth $d_{e, t}=33.06 \mathrm{~m}$ was for $\eta=0.1$ 296 and $\beta=0.05$, which is about $2.6 \%$ higher than that for ideal Tresca material. This gap reduces 297 gradually and finally the lowest embedment depth of $d_{e, t}=30.4 \mathrm{~m}$ was for $\eta=1.5$ and $\beta=0.2$, 298 which is about 5.6\% lower than that for ideal Tresca material. 
301 In order to show the effect of soil ductility, time-penetration profiles are shown in Figure 5 for $302 \xi_{95}=20$ and $30\left(\mathrm{Vi}=20 \mathrm{~m} / \mathrm{s}, \eta=1.0, \beta=0.1, \delta_{\text {rem }}=0.33, \dot{\gamma}_{\text {ref }}=0.1 / \mathrm{s}, \mathrm{kD} / \mathrm{sum}, \mathrm{ref}=0.43\right.$,

303 Sum,ref $/ \gamma^{\prime} \mathrm{D}_{\mathrm{A}}=0.78$; Table 1). The result for non-softening soil is included in the figure for 304 comparison. It is seen that the influence of soil brittleness on embedment is minimal and 305 increases slightly with decreasing strain softening parameter, $\xi_{95}$ (i.e. increasing brittleness).

306 For instance, for $\mathrm{v}_{\mathrm{i}}=20 \mathrm{~m} / \mathrm{s}$ in Figure 5, the embedment depth $\mathrm{d}_{\mathrm{e}, \mathrm{t}}$ increases from 31.88 to $307 \quad 32.16 \mathrm{~m}$ (i.e. $0.8 \%$ ) as $\xi_{95}$ reduces from 30 to 20.

\section{Effect of Soil Sensitivity $\left(\mathbf{S}_{\mathbf{t}}\right)$}

309 Typical sensitivity values for marine clays may range from 2 to 5 (Kvalstad et al. 2001; 310 Andersen and Jostad 2004; Randolph 2004; Menzies and Roper 2008; Lunne et al. 2011; 311 Gaudin et al. 2014). The effect of soil sensitivity, and hence remoulded strength ratio, $\delta$ rem,

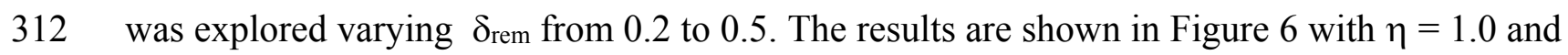
$3131.5, \beta=0.1$ and $0.2, \xi_{95}=20, \dot{\gamma}_{\text {ref }}=0.1 \mathrm{~s}^{-1}\left(\mathrm{kD}_{\mathrm{A}} /\right.$ sum,ref $=0.43$ and sum,ref $/ \gamma^{\prime} \mathrm{D}_{\mathrm{A}}=0.78$; Table 1). 314 As expected, the embedment depth increases with increasing soil sensitivity $\left(\mathrm{S}_{\mathrm{t}}\right)$. For instance, 315 for $\eta=1.0$ and $\beta=0.1$, the highest embedment depth, $d_{e, t}=32.39 \mathrm{~m}$ for $\mathrm{S}_{\mathrm{t}}=5$, which is about $3162 \%$ higher than that for $\mathrm{S}_{\mathrm{t}}=2$. Similar difference can be quantified for higher rate parameters $317 \quad(\eta=1.5, \beta=0.2)$.

\section{Combined Effects of Strain Rate, Strain Softening, and Soil Sensitivity}

319 In order to develop a design chart for estimating the embedment depth, the relationships 320 between strain rate and strength-softening were identified from all the anchor penetration 321 analyses tabulated in Table 1. It was found that the final embedment depth of anchor was 
approximately inverse proportional to the strain rate parameters $(\eta$ and $\beta$ ) and the strain softening parameters $\left(\delta_{\text {rem }}\right.$ and $\left.\xi_{95}\right)$.

324 From the parametric study encompassing a range of relevant values of $\eta=0 \sim 1.5$, $325 \beta=0.05 \sim 0.2, \xi_{95}=20 \sim 30$, and $\delta_{\text {rem }}=0.2 \sim 0.5$ (see Table 1), it is attempted to develop an approximate expression for anchor embedment depth, de,t, accounting for the combined effects of strain rate and strain softening. The results for soil with su,ref $=5+2 \mathrm{z} \mathrm{kPa}$

$328\left(\mathrm{kDA} /\right.$ sum,ref $=0.43$, sum,ref $\left./ \gamma^{\prime} \mathrm{D}_{\mathrm{A}}=0.78\right)$ are presented in Figures $7 \mathrm{a} \sim 7 \mathrm{~d}$ with the normalised embedment depth, $d_{e, t} / D_{p}$, plotted against viscosity property $\eta$ for different $\beta$ and $\xi_{95}$. Values 330 for strain-softened clay follow the similar trend, but lie well below the curve for non331 softening clay, reflecting the reduction in average strength ratio within the failure mechanism, 332 which increases final anchor embedment.

333 A convenient expression for estimating the normalised embedment depth, $d_{e, t} / D_{p}$, in rate 334 dependent and strain-softened clay is expressed as

$$
\frac{\mathrm{d}_{\mathrm{e}, \mathrm{t}}}{\mathrm{D}_{\mathrm{p}}}=\frac{1+\eta}{\left[1+\eta\left(\mathrm{R}_{\mathrm{a}}\right)^{\beta}\right]\left[\delta_{\text {rem }}+\left(1-\delta_{\text {rem }}\right) \mathrm{e}^{-3 \xi_{\mathrm{a}} \xi_{95}}\right]}\left(\frac{\mathrm{d}_{\mathrm{e}, \mathrm{t}}}{\mathrm{D}_{\mathrm{p}}}\right)_{\text {ideal }}
$$

336 where $\left(d_{e, t} / D_{p}\right)$ ideal is the value of $d_{e, t} / D_{p}$ obtained for an ideal rate independent, non-softening 337 Tresca material. This expression is calibrated with results from LDFE analyses in Figure 7 for $338 \delta_{\text {rem }}=0.33($ a sensitivity of 3$)$ and $\mathrm{V}_{\mathrm{i}}=20 \mathrm{~m} / \mathrm{s}$. Although there is some cross-coupling 339 between the effects of strain rate and strain softening, the multiplicative factors given in 340 Equation 3 appear sufficiently accurate taking $\mathrm{R}_{\mathrm{a}}=2.0$ and $\xi_{\mathrm{a}}=0.35$. The value of $\xi_{\mathrm{a}}$ 341 represents an average cumulative shear strain experienced by soil particles as they traverse the

342 flow mechanism around the anchor. The value of rate coefficient $\mathrm{R}_{\mathrm{a}}$ reflects the higher 343 average shear strain rate in the flow mechanism compared with the reference value. As shown 
344 in Figure $7 b$, net influences of $\eta$ and $\beta$ for different $\xi_{95}$ are almost identical, that is, all values

345 are in similar proportion to the curve for non-softening but rate dependent soil.

\section{Effect of Reference Strain Rate $\left(\dot{\gamma}_{\text {ref }}\right)$}

347 In LDFE analysis results presented so far, the soil strength $\mathrm{su}_{\mathrm{u}, \mathrm{ref}}=5+2 \mathrm{z} \mathrm{kPa}\left(\mathrm{kD}_{\mathrm{A}} / \mathrm{sum}_{\mathrm{um}}\right.$ ref $=$ 3480.43 , sum,ref $\left./ \gamma^{\prime} \mathrm{D}_{\mathrm{A}}=0.78\right)$, impact velocity $\left(\mathrm{v}_{\mathrm{i}}=20 \mathrm{~m} / \mathrm{s}\right)$ and reference shear strain rate $\left(\dot{\gamma}_{\text {ref }}=\right.$ $3490.1 \mathrm{~s}^{-1}$ ) were all kept constant. The rate coefficient, $\mathrm{R}_{\mathrm{a}}$, of 2.0 is applicable to the normalised 350 velocity $\mathrm{v}_{\mathrm{i}} / \mathrm{D}_{\mathrm{A}} \dot{\gamma}_{\mathrm{ref}}=186.92$. In the field, torpedo anchor normalised penetration rate, $\mathrm{v}_{\mathrm{i}} / \mathrm{D}_{\mathrm{A}}$, 351 may vary between 13 and $44\left(\mathrm{v}_{\mathrm{i}}=15 \sim 35 \mathrm{~m} / \mathrm{s}, \mathrm{D}_{\mathrm{A}}=0.8 \sim 1.2 \mathrm{~m}\right)$. In addition, reference shear 352 strain rates, at which su,ref was measured, may be different, with rates for laboratory triaxial 353 test $\left(\sim 0.00001 \mathrm{~s}^{-1}\right)$, T-bar and ball penetrometer tests $\left(0.001 \sim 0.1 \mathrm{~s}^{-1}\right)$, vane shear and viscometer tests $\left(0.01 \sim 100 \mathrm{~s}^{-1}\right)$ and fall cone test $\left(1 \sim 10 \mathrm{~s}^{-1}\right)$. An equivalent embedment depth for other normalised velocities may be obtained by adjusting the rate dependent term accordingly by the ratio of normalised velocities. Such adjustment would lead to negligible

357 rate effect for $\mathrm{v}_{\mathrm{i}} / \mathrm{D}_{\mathrm{A}} \dot{\gamma}_{\text {ref }}=10 \sim 20$. In general though, anchor embedment depth would 358 increase with increasing $\dot{\gamma}_{\text {ref }}$.

359 In order to investigate the effect of $\mathrm{v}_{\mathrm{i}} / \mathrm{D}_{\mathrm{A}} \dot{\gamma}_{\text {ref }}$ on the embedment depth, analyses were carried

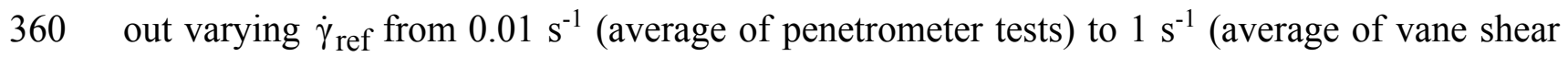
361 test and lower bound of fall cone test), but maintaining $\mathrm{v}_{\mathrm{i}}=20 \mathrm{~m} / \mathrm{s}$ and $\mathrm{D}_{\mathrm{A}}=1.07 \mathrm{~m}$ (Table 1). 362 The results are plotted in Figure 8 together with the curve for $\mathrm{vi}_{\mathrm{i}} / \mathrm{D}_{\mathrm{A}} \dot{\gamma}_{\text {ref }}=186.9$. And indeed, 363 the embedment depth is $\sim 5 \%$ lower for $\mathrm{v}_{\mathrm{i}} / \mathrm{D}_{\mathrm{A}} \dot{\gamma}_{\text {ref }}=1869.16\left(\dot{\gamma}_{\text {ref }}=0.01 \mathrm{~s}^{-1}\right)$ and $\sim 5 \%$ higher 364 for $\mathrm{v}_{\mathrm{i}} / \mathrm{D}_{\mathrm{A}} \dot{\gamma}_{\text {ref }}=18.69\left(\dot{\gamma}_{\text {ref }}=1 \mathrm{~s}^{-1}\right)$ compared to that for $\mathrm{v}_{\mathrm{i}} / \mathrm{D}_{\mathrm{A}} \dot{\gamma}_{\text {ref }}=186.9\left(\dot{\gamma}_{\text {ref }}=0.1 \mathrm{~s}^{-1}\right)$. 
365 Reference shear strain rate $\dot{\gamma}_{\text {ref }}$ is directly linked to Su,ref. Parametric analyses are carried out

366 isolating parameters. The effect of $\dot{\gamma}_{\text {ref }}$ is highlighted in this section, with the effect of

367 reference shear strength (and $\mathrm{v}_{\mathrm{i}}$ ) discussed in the following sections. This systematic 368 investigation is consistent with the ones undertaken by e.g. Hossain and Randolph (2009) for 369 spudcan foundations.

\section{$370 \quad$ Effect of Impact Velocity $\left(\mathbf{v}_{\mathbf{i}}\right)$}

371 Additionally, to show the effect of impact velocity $\left(\mathrm{v}_{\mathrm{i}}\right)$, time-penetration profiles are presented 372 in Figures $9 \mathrm{a}$ and $9 \mathrm{~b}$ for varying $\mathrm{vi}_{\mathrm{i}}(15 \sim 30 \mathrm{~m} / \mathrm{s})$ and rate parameters, but keeping other 373 parameters as constant $\left(\xi_{95}=20, \delta_{\text {rem }}=0.33, \dot{\gamma}_{\text {ref }}=0.1 \mathrm{~s}^{-1}, \mathrm{kD} /\right.$ sum,ref $=0.43$, Sum,ref $/ \gamma^{\prime} \mathrm{D}_{\mathrm{A}}=$ 374 0.78; Table 1). From Figure 9, the net increase in velocity at shallow embedment (Stage 1) is 375 seen to reduce as the impact velocity increases. This is to be expected as the closer the impact 376 velocities approach the anchor's terminal velocity, the less acceleration will occur within the soil. The anchor penetration depth at which the anchor begins to decelerate is also seen to be 378 reduced with increasing impact velocity (see Figure 9b). A consistent trend was reported by 379 O'Loughlin et al. (2013) analysing centrifuge model test data.

380 Overall, the embedment depth increases significantly with increasing impact velocity. 381 Interestingly, the influencing ratio of strain rate and softening on the embedment depth is 382 similar despite different impact velocities. For instance, for $v_{i}=15 \mathrm{~m} / \mathrm{s}$ in Figure 9, the 383 highest embedment depth $d_{e, t}=30.01 \mathrm{~m}$ was for $\eta=0.1, \beta=0.05, \xi_{95}=20$ and $\delta_{\text {rem }}=0.33$

384 which is about $8.1 \%$ higher than that for $\eta=1.5, \beta=0.15$ and $\delta_{\text {rem }}=1$. This gap remains 385 somewhat constant $(\sim 8.0 \%)$ as the impact velocity increases from $20 \mathrm{~m} / \mathrm{s}$ to $30 \mathrm{~m} / \mathrm{s}$. 
Effect of Reference Shear Strength $s_{u, r e f}$ or Soil Strength Non-homogeneity $\left(k D_{A} / s_{u m, r e f}\right)$

Initial use of torpedo anchors took place at Marlim Field, Albacora Leste Field and Corvina

Field in the Campos Basin (Medeiros 2002; Argiolas and Rosas 2003; de Araujo et al. 2004;

Brandão et al. 2006). A similar concept has been used at the Vøring Plateau, Troll Field and

Gjøa Field in the North Sea (Lieng et al. 2010; Sturm et al. 2011) and in the Gulf of Mexico

(Wodehouse et al. 2007; Zimmerman et al. 2009). Hossain et al. (2014) provided a summary

of these field tests. In these regions, seabed sediments are mostly composed of normally consolidated clay, with strength increasing somewhat linearly with depth. Typical strengths at the seabed level of $\mathrm{sum}=2 \sim 15 \mathrm{kPa}$, and gradients, $\mathrm{k}$, in the range of $0 \sim 3 \mathrm{kPa} / \mathrm{m}$. The effective unit weight of soil, $\gamma^{\prime}$, typically varies between 5 and $9 \mathrm{kN} / \mathrm{m}^{3}$. In order to examine the corresponding effect on the embedment depth in rate dependent and strain softening clay, analyses were also undertaken for $\mathrm{su}_{\text {,ref }}=1+1 \mathrm{z} \mathrm{kPa}\left(\mathrm{kD}_{\mathrm{A}} / \mathrm{sum}, \mathrm{ref}=1.07\right.$, sum,ref $\left./ \gamma^{\prime} \mathrm{D}_{\mathrm{A}}=0.16\right)$ and $\mathrm{su, \text {ref }}=10+3 \mathrm{z} \mathrm{kPa}\left(\mathrm{kD}_{\mathrm{A}} / \mathrm{sum, \text {ref }}=0.32, \mathrm{sum}, \mathrm{ref} / \gamma^{\prime} \mathrm{D}_{\mathrm{A}}=1.56\right)$, and the results are shown in

Figure 10. The curve for $\mathrm{su,ref}=5+2 \mathrm{z} \mathrm{kPa}\left(\mathrm{kD}_{\mathrm{A}} / \mathrm{sum}_{\mathrm{u}, \mathrm{ref}}=0.43, \mathrm{sum}_{\text {,ref }} / \gamma^{\prime} \mathrm{D}_{\mathrm{A}}=0.78\right)$ is also included in Figure 10 for comparison. The curve for lower shear strength (lower nonhomogeneity, but higher normalised strength) attain to a plateau earlier, resulting in a lower embedment depth. It is seen that effect of $\mathrm{su,ref}$ and $\mathrm{kD}_{\mathrm{A}} / \mathrm{sum}_{\mathrm{u}, \mathrm{ref}}$, sum,ref $/ \gamma^{\prime} \mathrm{D}_{\mathrm{A}}$ is markedly profound relative to other effects as the soil undrained shear strength is the dominant factor for anchor penetration resistance in stage 2 (see later Equation 4). Compared to that $\left(\mathrm{d}_{\mathrm{e}, \mathrm{t}}=\right.$ $32.16 \mathrm{~m})$ for $\mathrm{Su}, \mathrm{ref}=5+2 \mathrm{z} \mathrm{kPa}\left(\mathrm{kDA}_{\mathrm{A}} /\right.$ sum,ref $=0.43$, sum,ref $\left./ \gamma^{\prime} \mathrm{D}_{\mathrm{A}}=0.78\right)$, the embedment depth for $\mathrm{Su}$, ref $=1+1 \mathrm{z} \mathrm{kPa}\left(\mathrm{kDA} / \mathrm{Sum}\right.$, ref $=1.07$, sum,ref $\left./ \gamma^{\prime} \mathrm{D}_{\mathrm{A}}=0.16\right)$ is $35 \%$ higher and for $\mathrm{su,ref}=10+$ $3 \mathrm{z} \mathrm{kPa}\left(\mathrm{kDA}_{\mathrm{A}} /\right.$ sum,ref $=0.32$, sum,ref $\left./ \gamma^{\prime} \mathrm{D}_{\mathrm{A}}=1.56\right)$ is $16 \%$ lower. 


\section{Prediction of Embedment Depth in Field}

412

413

414

415

416

417

418

419

420

421

422

426

427

$$
\begin{aligned}
\mathrm{m} \frac{\mathrm{d}^{2} \mathrm{z}}{\mathrm{dt}^{2}}= & \mathrm{W}_{\mathrm{s}}-\mathrm{F}_{\gamma}-\mathrm{R}_{\mathrm{f} 1} \mathrm{~F}_{\mathrm{b}}-\mathrm{R}_{\mathrm{f} 2} \mathrm{~F}_{\mathrm{f}}-\mathrm{F}_{\mathrm{d}} \\
= & \mathrm{W}_{\mathrm{s}}-\mathrm{F}_{\gamma}-\mathrm{R}_{\mathrm{f} 1}\left(\mathrm{~F}_{\mathrm{b}, \mathrm{bA}}+\mathrm{F}_{\mathrm{b}, \mathrm{bF}}\right)-\mathrm{R}_{\mathrm{f} 2}\left(\mathrm{~F}_{\mathrm{fA}}+\mathrm{F}_{\mathrm{fF}}\right)-\mathrm{F}_{\mathrm{d}} \\
= & \mathrm{W}_{\mathrm{s}}-\mathrm{F}_{\gamma}-\mathrm{R}_{\mathrm{f} 1}\left(\mathrm{~N}_{\mathrm{c}, \mathrm{bA}} \mathrm{s}_{\mathrm{u}, \mathrm{bA}} \mathrm{A}_{\mathrm{A}}+\mathrm{N}_{\mathrm{c}, \mathrm{bF}} \mathrm{s}_{\mathrm{u}, \mathrm{bF}} \mathrm{A}_{\mathrm{bF}}\right)-\alpha \mathrm{R}_{\mathrm{f} 2}\left(\mathrm{~s}_{\mathrm{u}, \mathrm{sA}} \mathrm{A}_{\mathrm{sA}}+\mathrm{s}_{\mathrm{u}, \mathrm{sF}} \mathrm{A}_{\mathrm{sF}}\right) \\
& -\frac{1}{2} \mathrm{C}_{\mathrm{d}} \rho_{\mathrm{s}} \mathrm{A}_{\mathrm{p}} \mathrm{v}^{2}
\end{aligned}
$$

The terms used in the above expression are defined under nomenclature. $\mathrm{R}_{\mathrm{f} 1}$ and $\mathrm{R}_{\mathrm{f} 2}$ are shear strain rate and softening related terms for end bearing and frictional resistance, respectively.

\section{Extended Bearing Resistance Method}

Validation was undertaken against field data on a 4-fin torpedo anchor, as reported by Brandão et al. (2006). Eighteen torpedo anchors $\left(\mathrm{W}_{\mathrm{s}}=850 \mathrm{kN}, \mathrm{D}_{\mathrm{A}}=1.07 \mathrm{~m}, \mathrm{~L}_{\mathrm{A}}=17 \mathrm{~m}, \mathrm{LF}_{\mathrm{F}}=\right.$ $10 \mathrm{~m}$ and $\left.\mathrm{WF}_{\mathrm{F}}=0.9 \mathrm{~m}\right)$ were installed in a soft normally consolidated clay deposit $(\mathrm{su}, \mathrm{ref} \approx 5+$ $2 \mathrm{z} \mathrm{kPa} ; \mathrm{kD}_{\mathrm{A}} / \mathrm{Sum}, \mathrm{ref}=0.43$ and sum,ref $\left./ \gamma^{\prime} \mathrm{D}_{\mathrm{A}}=0.78\right)$ at Campos basin, Brazil. The achieved impact velocity was $\mathrm{vi}_{\mathrm{i}} \approx 26.8 \mathrm{~m} / \mathrm{s}$ and the average penetrations were about $35.2 \mathrm{~m}$. The objective in this part is to compare predicted penetrating depth profile obtained using a bearing resistance method.

The motion response of a torpedo anchor during dynamic embedment in soil may be approached by considering Newton's second law of motion and the forces acting on the anchor during penetration. Several studies (Medeiros 2002; de Araujo et al. 2004; Brandão et al. 2006; Richardson et al. 2009; O'Loughlin et al. 2009, 2013, Chow et al. 2014; Hossain et al. 2014, 2015; Kim et al. 2015) have adopted such an approach, with variations on the inclusion and formulation of the various forces acting on a torpedo anchor. A similar approach is adopted here
The frictional resistance term $\left(F_{f}\right)$ comprises friction along the shaft $\left(F_{f A}\right)$ and the fins $\left(F_{f F}\right)$, 
while the bearing resistance term $\left(\mathrm{F}_{\mathrm{b}}\right)$ includes end bearing at the base of the shaft $\left(\mathrm{F}_{\mathrm{b}, \mathrm{bA}}\right)$ and fins $\left(\mathrm{F}_{\mathrm{b}, \mathrm{bF}}\right)$. In addition, if soil backflow occurs above the installing anchor, reverse end bearing at the upper end of the shaft $\left(\mathrm{F}_{\mathrm{b}, \mathrm{tA}}\right)$ and fins $\left(\mathrm{F}_{\mathrm{b}, \mathrm{t}}\right)$ must be accounted for. $\mathrm{W}_{\mathrm{s}}$ is the submerged weight (in water) of the anchor and $F_{\gamma}$ is a buoyancy force, calculated as the displaced volume times the effective unit weight of the soil $\left(\gamma^{\prime}\right) . \quad F_{d}$ is the inertial 'drag' resistance generally expressed in terms of a drag coefficient, $C_{d}$, as indicated (with $\rho_{s}$ the submerged soil density and $\mathrm{v}$ the velocity of the penetrating anchor). During the penetration process, soil is displaced from the path of the advancing anchor. Soil elements are accelerated from rest to a velocity sufficient to move them out of the path of the anchor. The force required to accelerate the soil elements is known as an inertial force. The reaction to the inertial force produces a resistance force on the anchor. Inertial drag resistance in soil is analogous to the hydrodynamic drag experienced by an object passing through water. Considering the very soft, viscous clay typically present at the seabed surface it seems reasonable to assume that an inertial drag force exists during penetration (Richardson et al. 2009; Hasanloo et al. 2012).

The dependence of shear strength on shear strain rate and strain softening can be generally formulated using Equation 5 and has been accounted for in Equation 4 by scaling the bearing resistances by a rate function, $\mathrm{R}_{\mathrm{f} 1}$, expressed as

$$
\mathrm{R}_{\mathrm{f} 1}=\frac{1}{(1+\eta)}\left[1+\eta\left(\frac{\mathrm{nv} / \mathrm{D}_{\mathrm{A}}}{\dot{\gamma}_{\text {ref }}}\right)^{\beta}\right]\left[\delta_{\text {rem }}+\left(1-\delta_{\text {rem }}\right) \mathrm{e}^{-3 \xi_{\mathrm{a}} / \xi_{95}}\right]
$$

In this analysis, values for the various parameters were adopted as follows: $C_{d}=0.63$ (Lieng et al. 1999, 2000, 2010; Sturm et al. 2011; O’Loughlin et al. 2013), $\mathrm{n}=1.0, \mathrm{~N}_{\mathrm{c}, \mathrm{bA}}=13.56$, $\mathrm{N}_{\mathrm{c}, \mathrm{bF}}=7.5, \eta=1.0, \beta=0.1, \delta_{\mathrm{rem}}=1 / \mathrm{S}_{\mathrm{t}}=1 / 3$, and $\xi_{95}=20$. For the frictional resistance, $\mathrm{R}_{\mathrm{f} 2}$ was taken as $2 R_{f 1}$ from the previous reports (Einav and Randolph 2006; Chow et al. 2014; 
454 Steiner et al. 2014). The predictions made the same assumptions based on the findings from 455 the parametric studies, adopting $\dot{\gamma}_{\text {ref }}=0.1 \mathrm{~s}^{-1}$ and $\xi_{\mathrm{a}}=0.35$.

456 Figure 11a shows the measured (Brandão et al. 2006), computed (LDFE analysis) and 457 predicted velocity-penetration profiles using Equations 4 and $5\left(\mathrm{kD}_{\mathrm{A}} / \mathrm{sum}, \mathrm{ref}=0.43\right.$, sum,ref $/ \gamma^{\prime} \mathrm{D}_{\mathrm{A}}$ $458=0.78)$. The estimated profiles assuming ideal rate independent, non-softening $\left(\eta=0, \delta_{\text {rem }}=\right.$ 4591 ; Equation 5) and rate dependent, non-softening $\left(\delta_{\text {rem }}=1\right.$; Equation 5) soil are also included 460 in the figure. Overall, the computed and predicted curves for rate dependent and softening soil 461 closely predict the general trend of the measured data, and the predicted embedment depth $462\left(\mathrm{de}_{\mathrm{e}, \mathrm{t}}\right)$ also shows a good agreement with an error of $< \pm 4.0 \%$. Lower and significantly higher 463 embedment depths were resulted for rate dependent, non-softening and rate independent, non464 softening soil respectively, confirming the necessity of considering in particular rate 465 dependency for this dynamic installation problem. The motion of the anchor and hence the 466 magnitude of the penetration resistance forces may be estimated from Equations 4 and 5. The 467 contributions of these resistance forces are plotted in Figure 11b. The figure confirms that the 468 total resistance force at relatively shallow depths (Stage 1, acceleration stage) does not exceed 469 the weight of the anchor.

\section{Extended Modified Energy Method}

471 Recently, O'Loughlin et al. (2013) proposed a simple expression utilising a dataset of 472 centrifuge testing. Total energy $\left(E_{\text {total }}\right)$, defined as the sum of the kinetic energy of the anchor 473 at the mudline and the potential energy released as it penetrates in the seabed, normalised by $\mathrm{k}$ 474 and $\mathrm{D}_{\mathrm{p}}{ }^{4}$ (i.e. $\left.\mathrm{E}_{\text {total }} / \mathrm{kD}_{\mathrm{p}}{ }^{4}\right)$ were used to link to the normalised embedment depth $\left(\mathrm{d}_{\mathrm{e}, t} / \mathrm{D}_{\mathrm{p}}\right)$. In an 475 attempt to improve the total energy method, Kim et al. (2015) carried out a series of LDFE 476 analyses for various anchor configurations (but with a fixed series of strain rate and softening parameters: $\left.\dot{\gamma}_{\text {ref }}=0.1 \mathrm{~s}^{-1}, \eta=1.0, \beta=0.1, \delta_{\text {rem }}=1 / \mathrm{S}_{\mathrm{t}}=1 / 3, \xi_{95}=20\right)$ and modified it as a 
478 function of $E_{t o t a l} / \mathrm{kA}_{s} \mathrm{D}_{\mathrm{p}}{ }^{2}$ accounting for the contribution of the total surface area of the anchor

$479 \quad\left(\mathrm{~A}_{\mathrm{s}}=\mathrm{A}_{\mathrm{sA}}+\mathrm{A}_{\mathrm{sF}}\right)$ as

480

$$
\frac{\mathrm{d}_{\mathrm{e}, \mathrm{t}}}{\mathrm{D}_{\mathrm{p}}}=4.0\left(\frac{\mathrm{E}_{\text {total }}}{\mathrm{kA}_{\mathrm{s}} \mathrm{D}_{\mathrm{p}}^{2}}\right)^{0.389}
$$

481 where

$$
\mathrm{E}_{\text {total }}=\frac{1}{2} \mathrm{mv}_{\mathrm{i}}^{2}+\mathrm{m}^{\prime} \mathrm{gd}_{\mathrm{e}, \mathrm{t}}
$$

483 with $\mathrm{m}^{\prime}$ being the effective mass of the anchor (submerged in soil), g Earth's gravitational 484 acceleration of $9.81 \mathrm{~m} / \mathrm{s}^{2}$ and $\mathrm{D}_{\mathrm{p}}$ the anchor projected area equivalent diameter (including 485 fins). Figure 12 shows the relationship following Equation 6, and data for various velocities 486 and strain rate and strain softening parameters. For each combination of $\beta$ and $\delta_{\text {rem }}$ (or non487 softening), four analyses were carried out varying $\eta$ as $0,0.5,1.0$ and 1.5 , as labelled in 488 Figure 12. By comparing the result for the set parameter $\left(\eta=1.0, \beta=0.1, \delta_{\text {rem }}=1 / \mathrm{S}_{\mathrm{t}}=\right.$ $4891 / 3, \xi_{95}=20$ ), anchor embedment depth decreases or increases depending on increasing or 490 decreasing of the degree of rate dependency and the inverse of the sensitivity of the soil. From 491 the parametric study encompassing a range of relevant values of $\eta=0.1 \sim 1.5 ; \beta=0.05 \sim$ 492 $0.2 ; \delta_{\text {rem }}=0.2 \sim 0.5$; and $\xi_{95}=20 \sim 30$ (see Table 1), Equation 6 , accounting for the 493 combined effects of strain rate and strain softening, may be re-written with a multiplicative 494 term as

$$
\frac{\mathrm{d}_{\mathrm{e}, \mathrm{t}}}{\mathrm{D}_{\mathrm{p}}}=\frac{1+\eta}{\left[1+\eta\left(\mathrm{R}_{\mathrm{b}}\right)^{\beta}\right]\left[\delta_{\text {rem }}+\left(1-\delta_{\mathrm{rem}}\right) \mathrm{e}^{\left.-3 \xi_{\mathrm{b}} / \xi_{95}\right]}\right.} 4.0\left(\frac{\mathrm{E}_{\text {total }}}{\mathrm{kA}_{\mathrm{s}} \mathrm{D}_{\mathrm{p}}^{2}}\right)^{0.389}
$$

496 By comparing this expression with modified energy method, as shown in Figure 12, values 497 for the parameters $\mathrm{R}_{\mathrm{b}}$ and $\xi_{\mathrm{b}}$ may be estimated $\mathrm{as} \mathrm{R}_{\mathrm{b}} \sim 1.8$ and $\xi_{\mathrm{b}} \sim 0.28$. The rate coefficient 
and average cumulative shear strain in Figure 7 are slightly higher $\left(\mathrm{R}_{\mathrm{a}}=2.0, \xi_{\mathrm{a}}=0.35\right)$, since

499 the last term of Equation 3 obtained for an ideal rate independent, non-softening clay. Figure

50012 confirms, as shown by two bound lines, that the modified method with multiplication term

501 (Equation 8) can predict anchor embedment depths accurately for various range of strain rate 502 dependency, strain softening, soil strength and sensitivity, and anchor impact velocity.

\section{Concluding Remarks}

505

Dynamic installation of a typical torpedo anchor was investigated extensively through 3D dynamic large deformation finite element analyses. The embedment depth of the anchor was found to be a function of the impact velocity, strain rate dependency of the shear strength, degree of remoulding during shearing (or strain softening) and hence sensitivity of the soil. The effect of the geometric parameters of torpedo anchors such as the length and diameter of the shaft; number, width and length of fins; and the undrained shear strength of seabed sediments were reported by Kim et al. (2015).

Overall, the effect of strain rate dependency on the anchor penetration profile was found to dominate. Although the effects of rate dependency were partly compensated for by an increase in penetration depth resistance due to strain softening, the strain rates involved were very high (i.e. the softening was relatively quite small), resulting in correspondingly small strain softening effects. During penetration of the anchor, the mobilised soil strength was affected by strain rate and accumulated strain softening simultaneously. The soil with larger strain softening (lower strength) was also featured with higher strain rate, which tended to increase the soil strength, i.e. the effects of strain softening and strain rate in 'shear bands' are partly compensated each other. 
521 A robust total energy approach, modified from that proposed by O'Loughlin et al. (2013), was

522 proposed (Equation 8), taking into account the effect of anchor mass, impact velocity, surface

523 area, projected area equivalent diameter of the anchor, the soil undrained shear strength, strain

524 rate dependency of the shear strength, degree of remoulding during shearing (or strain

525 softening) and hence sensitivity of the soil.

\section{Acknowledgements}

528 The research presented here was undertaken with support from the National Research

529 Foundation of Korea (NRF) grant funded by the Korea Government (Ministry of Education,

530 Science and Technology: No. 2011-0030842 and NRF-2011-357-D00235) and the Australian

531 Research Council through the Discover Early Career Researcher Award DE140100903. The

532 work forms part of the activities of the Centre for Offshore Foundation Systems (COFS),

533 currently supported as a node of the Australian Research Council Centre of Excellence for

534 Geotechnical Science and Engineering, through Centre of Excellence funding from the State

535 Government of Western Australia and in partnership with The Lloyd's Register Foundation.

536 This support is gratefully acknowledged. 


\section{References}

542

Andersen, K.H., and Jostad, H.P. (2004). "Shear strength along inside of suction anchor skirt wall in clay." Proc. Offshore Technology Conf., Houston, OTC 16844.

Argiolas, R., and Rosas C. M. M. (2003). "Barracuda and Caratinga integrated deepwater site investigation, offshore Brazil." Proc. Offshore Technology Conf., Houston, OTC15265.

Biscontin, G., and Pestana, J. M. (2001). "Influence of peripheral velocity on vane shear strength of an artificial clay." Geotechnical Testing J., 24(4), 423-429.

Brandão, F. E. N., Henriques, C. C. D., de Araujo, J. B., Ferreira, O. C. G., and dos Santos Amaral, C. (2006). “Albacora Leste field development - FPSO P-50 mooring system concept and installation.” Proc. Offshore Technology Conf., Houston, OTC18243.

Boukpeti, N., White, D. J., and Randolph, M. F. (2012). "Strength of fine-grained soils at the solid-fluid transition." Géotechnique, 62(3), 213-226.

Chow, S. H., O’Loughlin, C. D., and Randolph, M. F. (2014). "A centrifuge investigation of free-fall piezocone in clay." Géotechnique, 64(10), 817-824.

Dassault Systemes (2011). ABAQUS, Version 6.11 EF Documentation. Rhode Island: Hibbitt, Karlsson \& Sorensen, Inc.

de Araujo, J. B., Machado, R. D., and de Medeiros Junior, C. J. (2004). "High holding power torpedo pile - results for the first long term application." Proc. $23^{\text {rd }}$ Int. Conf. Offshore Mechanics and Arctic Engineering, OMAE, Vancouver, OMAE2004-51201. 
DeGroot, D. J., DeJong, J. T., Yafrate, N. J., Landon, M. M., and Sheahan, T. C. (2007). "Application of recent developments in terrestrial soft sediment characterization methods to offshore environments." Proc. Offshore Technology Conf., Houston, OTC18737.

DeJong, J., DeGroot, D., and Yafrate, N. (2012). "Evaluation of undrained shear strength using full-flow penetrometers.” J. Geotechnical and Geoenvironmental Engineering 138(6), 765-767.

Einav, I., Randolph, M. F., (2006). "Effect of strain rate on mobilised strength and thickness of curved shear bands." Géotechnique, 56(7), 501-504.

Gaudin, C., O’Loughlin, C.D. Hossain, M.S., Randolph, M.F., and Colliat, J.-L. (2014). "Installation of suction caissons in Gulf of Guinea clay." Proc. 8th Int. Conf. on Physical Modelling in Geotechnics, Perth, 1, 493-499.

Hasanloo, D. Pang, H., and Yu, G. (2012). "On the estimation of the falling velocity and drag coefficient of torpedo anchor during acceleration.” Ocean Engineering, 42, 135-146.

Herschel, W. H., and Bulkley, T. (1926). "Measurement of consistency as applied to rubberbenzene solutions.” Am. Soc. Test Proc., 26(2), 621-633.

Hossain, M. S., and Randolph, M. F. (2009). "Effect of Strain Rate and Strain Softening on the Penetration Resistance of Spudcan Foundations on Clay." Int. J. Geomechanics, ASCE, 9(3), 122-132.

Hossain, M. S., Kim, Y. H., and Gaudin, C. (2014). "Experimental investigation of installation and pull-out of dynamically penetrating anchors in clay and silt." $J$. Geotechnical and Geoenvironmental Engineering, ASCE, 140(7), 04014026. 
Hossain, M. S., O’Loughlin, C., and Kim, Y. H. (2015). "Dynamic Installation and 584 Monotonic Pullout of a Torpedo Anchor in Calcareous Silt." Géotechnique, 65(2), 7790.

Kim, Y. H., Hossain, M. S., Wang, D., and Randolph, M. F. (2015). "Numerical Investigation of Dynamic Installation of Torpedo Anchors in Clay." Ocean Engineering, Under review.

Kvalstad, T.J., Nadim, F., and Harbitz, C.B. (2001). "Deepwater geohazards: geotechnical concerns and solutions.” Proc. Offshore Technology Conf., Houston, OTC 16844.

Lieng, J. T., Hove, F., and Tjelta, T. I. (1999). "Deep Penetrating Anchor: Subseabed Deepwater Anchor Concept for Floaters and other Installations." Proc. 9th Int. Offshore and Polar Engineering Conference, Brest, 613-619.

Lieng, J. T., Kavli, A., Hove, F.m and Tjelta, T. I. (2000). “Deep Penetrating Anchor: Further Development, Optimization and Capacity Clarification." Proc. 10th Int. Offshore and Polar Engineering Conference, Seattle, 410-416.

Lieng, J. T., Tjelta, T. I., and Skaugset, K. (2010). "Installation of two prototype deep penetrating anchors at the Gjoa Field in the North Sea." Proc. Offshore Technology Conf., Houston, OTC20758.

Lunne, T., and Andersen, K. H. (2007). "Soft clay shear strength parameters for deepwater geotechnical design." Keynote address, Proc. $6^{\text {th }}$ Int. Offshore Site Investigation and Geotechnics Conf., London, UK, 151-176.

Lunne, T., Anderson, K.H., Low, H.E., Randolph, M.F., and Sjursen, M. (2011). “Guidelines for offshore in situ testing and interpretation in deepwater soft clays." Canadian 

system for flexible risers in deep waters." Proc. $34^{\text {th }}$ Offshore Technology Conf., Houston, OTC14151.

Menzies, D., and Roper, R. (2008). “Comparison of jackup rig spudcan penetration methods in clay." Proc. $34^{\text {th }}$ Offshore Technology Conf., Houston, OTC19545.

O’Loughlin, C. D., Richardson, M. D., and Randolph, M. F. (2009). "Centrifuge tests on dynamically installed anchors." Proc. $28^{\text {th }}$ Int. Conf. on Ocean, Offshore and Arctic Engineering, Honolulu, USA, OMAE80238.

O’Loughlin, C. D., Richardson, M. D., Randolph, M. F., and Gaudin, C. (2013). "Penetration of dynamically installed anchors in clay." Géotechnique, 63(11), 909-919.

Raie, M., and Tassoulas, J. (2009). “Installation of torpedo anchors: numerical modeling.” $J$. Geotechnical and Geoenvironmental Engineering, ASCE, 135(12), 1805-1813.

Randolph, M. F. (2004). “Characterisation of soft sediments for offshore applications.” Proc. $2^{\text {nd }}$ Int. Conf. on Geotechnical and Geophysical Site Characterisation, Porto 1, 209231.

Richardson, M.D., O’Loughlin, C.D., Randolph, M.F., and Gaudin, C. (2009). "Setup following installation of dynamic anchors in normally consolidated clay." J. Geotech. Geoenviron. Eng. ASCE, 135(4), 487-496.

Steiner A, Kopf A. J, L’Heureux J-S., Kreiter, S., Stegmann, S., Haflidason, H., and Moerz T. (2014). "In situ dynamic piezocone penetrometer tests in natural clayey soils - a reappraisal of strain-rate corrections." Canadian Geotechnical Journal, 51, 272-288. 
626 Sturm, H., Lieng, J. T., and Saygili, G. (2011). "Effect of soil variability on the penetration depth of dynamically installed drop anchors." Proc. Offshore Technology Conf., Houston, OTC22396.

629 Wodehouse, J., George, B., and Luo, Y. (2007). "The Development of a FPSO for the Deepwater Gulf of Mexico.” Proc. 39th Offshore Technology Conference, Houston, USA, Paper No. 18560.

632 Zimmerman, E. H., Smith, M. W. and Shelton, J. T. (2009). Efficient gravity installed anchor for deep water mooring. Proc. Offshore Technology Conf., Houston, OTC20117.

634 Zhou, H., and Randolph, M. F. (2009). "Resistance of full-flow penetrometers in rate635 dependent and strain-softening clay." Géotechnique, 59(2), 79-86.

636 Zhu, H., and Randolph, M. F. (2011). "Numerical analysis of a cylinder moving through ratedependent undrained soil." Ocean Engineering, 38, 943-953. 


\begin{tabular}{|c|c|c|c|c|c|c|c|}
\hline $\mathrm{kD} /$ sum,ref & Sum,ref $/ \gamma^{\prime} D_{A}$ & $\mathrm{Vi} / \mathrm{D}_{\mathrm{A}} \dot{\gamma}_{\mathrm{ref}}$ & $\eta$ & $\beta$ & $\xi_{95}$ & $\begin{array}{c}\delta_{\text {rem }} \\
\left(1 / \mathrm{S}_{\mathrm{t}}\right)\end{array}$ & Notes \\
\hline 0.43 & 0.78 & 186.91 & $\begin{array}{c}0,0.1,0.5 \\
1.0, \text { and } 1.5\end{array}$ & $\begin{array}{c}0.05,0.10 \\
0.15 \text { and } \\
0.20\end{array}$ & 20 & 0.33 & $\begin{array}{l}\text { Effect of } \eta \\
\quad \text { and } \beta\end{array}$ \\
\hline 0.43 & 0.78 & 186.91 & $\begin{array}{l}0,0.1,0.5 \\
1.0, \text { and } 1.5\end{array}$ & $\begin{array}{c}0.05,0.10 \\
0.15 \text { and } \\
0.20\end{array}$ & - & - & $\begin{array}{l}\text { Without } \\
\text { softening }\end{array}$ \\
\hline 0.43 & 0.78 & 186.91 & $\begin{array}{c}0.5,1.0 \text { and } \\
1.5\end{array}$ & 0.10 & $\begin{array}{c}20 \text { and } \\
30 \\
\end{array}$ & 0.33 & Effect of $\xi_{95}$ \\
\hline 0.43 & 0.78 & 186.91 & 1.0 and 1.5 & $\begin{array}{c}0.10 \text { and } \\
0.20\end{array}$ & 20 & $\begin{array}{c}0.20,0.33 \\
\text { and } 0.50 \\
(1 / 5,1 / 3 \\
1 / 2)\end{array}$ & Effect of $\delta$ rem \\
\hline 0.43 & 0.78 & $\begin{array}{c}18.69 \text { and } \\
1869\end{array}$ & 1.0 & 0.10 & 20 & 0.33 & $\begin{array}{c}\text { Effect of } \\
\dot{\gamma}_{\text {ref }}\end{array}$ \\
\hline 0.43 & 0.78 & - & - & - & - & - & $\begin{array}{c}\text { Ideal Tresca } \\
\text { material }\end{array}$ \\
\hline 1.07 & 0.16 & \multirow{2}{*}{186.91} & \multirow{2}{*}{1.0} & \multirow{2}{*}{0.10} & \multirow{2}{*}{20} & \multirow{2}{*}{0.33} & \multirow{2}{*}{$\begin{array}{l}\text { Effect of } \\
\mathrm{kD}_{\mathrm{A}} / \mathrm{sum}_{\text {,ref }}\end{array}$} \\
\hline 0.32 & 1.56 & & & & & & \\
\hline
\end{tabular}

640

641

642

643

644 
646 Figure 1. Schematic diagram of installed torpedo anchor in clay

647 Figure 2. Typical mesh used in CEL analysis: (a) Typical 3D mesh; (b) Detail plan view; (c) Side view

649 Figure 3. Effect of strain rate and strain softening on embedment depths and soil failure mechanisms $\left(\mathrm{LA}_{\mathrm{A}}=17 \mathrm{~m}, \mathrm{D}_{\mathrm{A}}=1.07 \mathrm{~m}, \mathrm{LF}_{\mathrm{F}}=10 \mathrm{~m}, \mathrm{WF}=0.9\right)$ : (a) Embedment depths; (b) Instantaneous (resultant) velocity vectors with anchor embedment; (c) Soil separation at shallow depth

Figure 4. Effect of strain softening parameters $\eta$ and $\beta$ on anchor embedment

654 Figure 5. Effect of strain softening parameter $\xi_{95}$ on anchor embedment depth

655 Figure 6. Effect of remoulded strength ratio $\delta_{\text {rem }}$ and soil sensitivity $S_{t}$ on anchor embedment depth

657

658

659

660

661

662

663

664

665

666

667

Figure 7. Combined effect of strain rate parameter $\eta, \beta$ and strain softening parameter $\xi_{95}$ on anchor embedment depth: (a) $\beta=0.05$; (b) $\beta=0.1$; (c) $\beta=0.15$; (d) $\beta=$ 0.2

Figure 8. Effect of reference shear strain $\dot{\gamma}_{\text {ref }}$ on anchor embedment depth

Figure 9. Effect of impact velocity vi on anchor embedment depth: (a) Time-embedment profile; (b) Velocity profile

Figure 10. Effect of soil undrained shear strength on anchor embedment depth

Figure 11. Measured vs estimated anchor installation profile using proposed bearing resistance method: (a) Comparison between measured field installation data and estimated profile; (b) Contribution of various resistance force components (Equation 4: rate dependent \& strain softening) 
668 Figure 12. Modified energy method for assessing anchor embedment depths: (a) 669 Estimation using modified energy method; (b) Magnification of numerical 670 dataset

671 


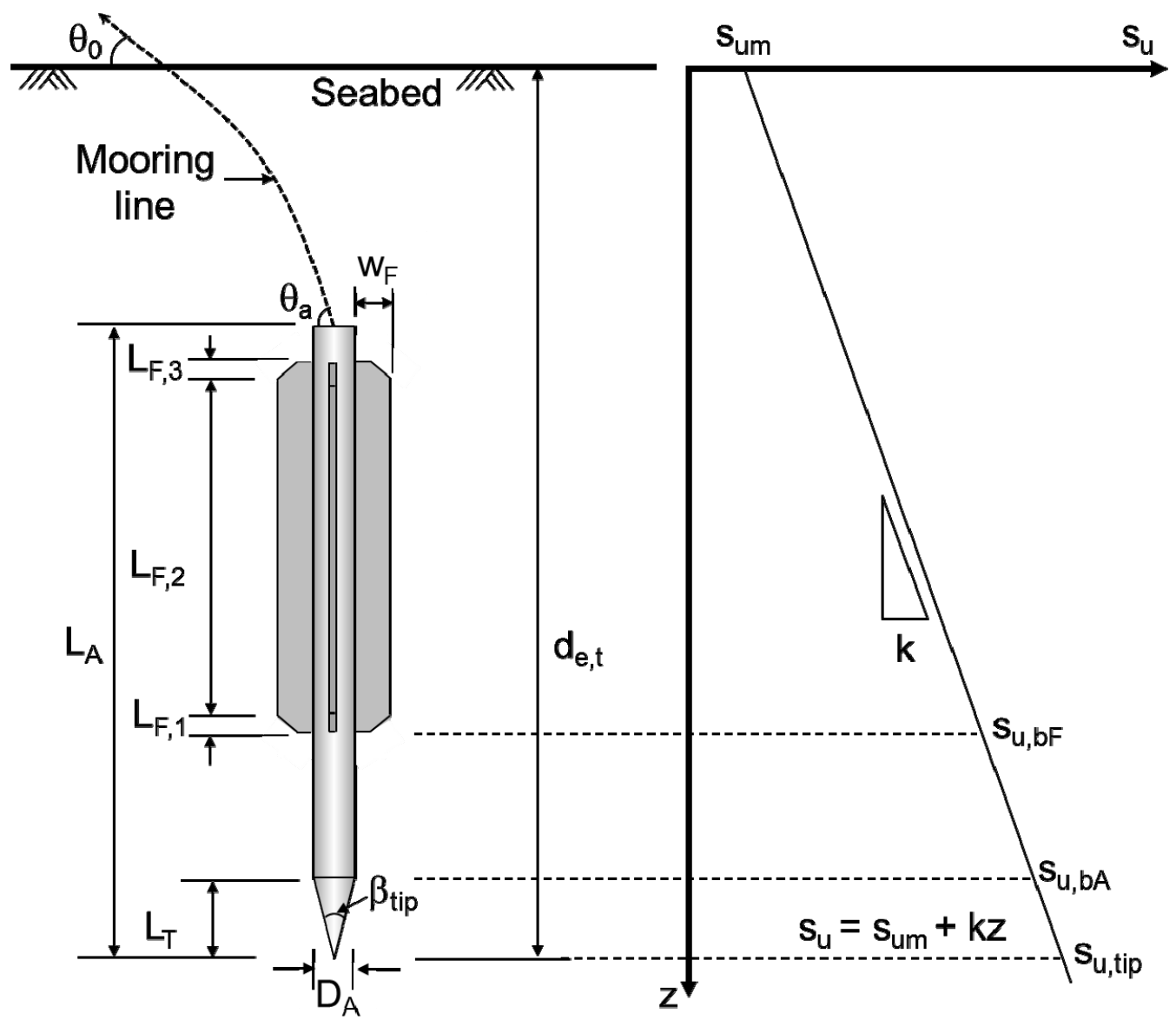

673

674

675

676

Figure 1. Schematic diagram of installed torpedo anchor in clay 677 
678

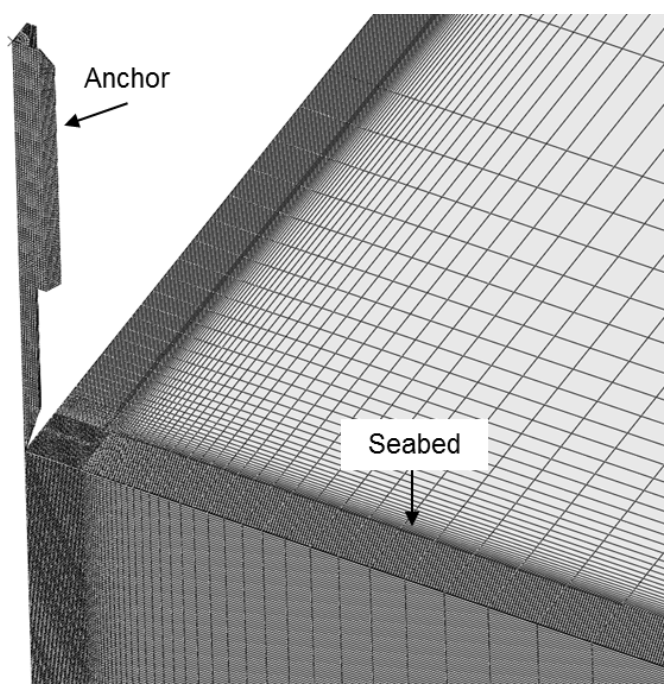

(a) Typical 3D mesh

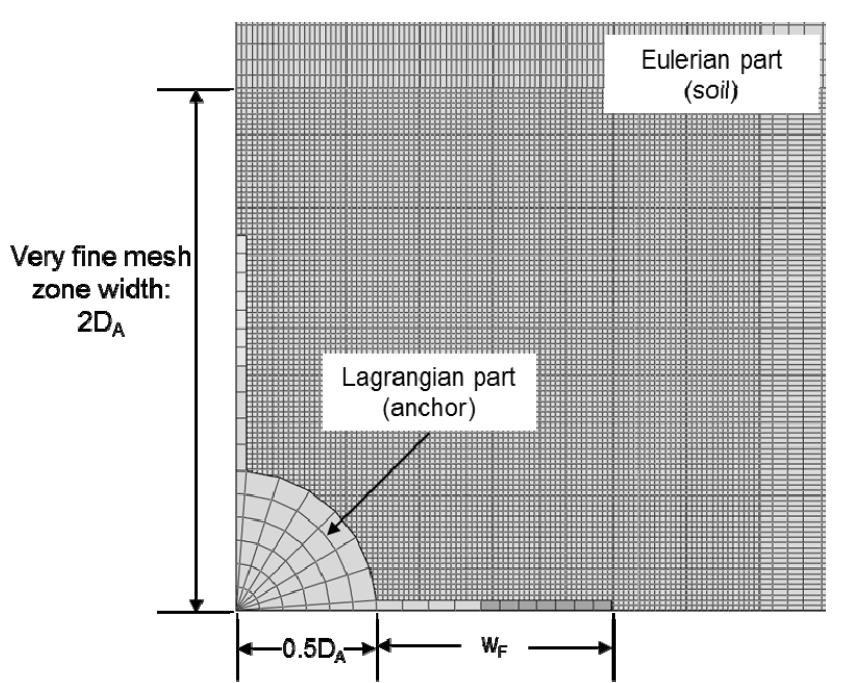

(b) Detail plan view

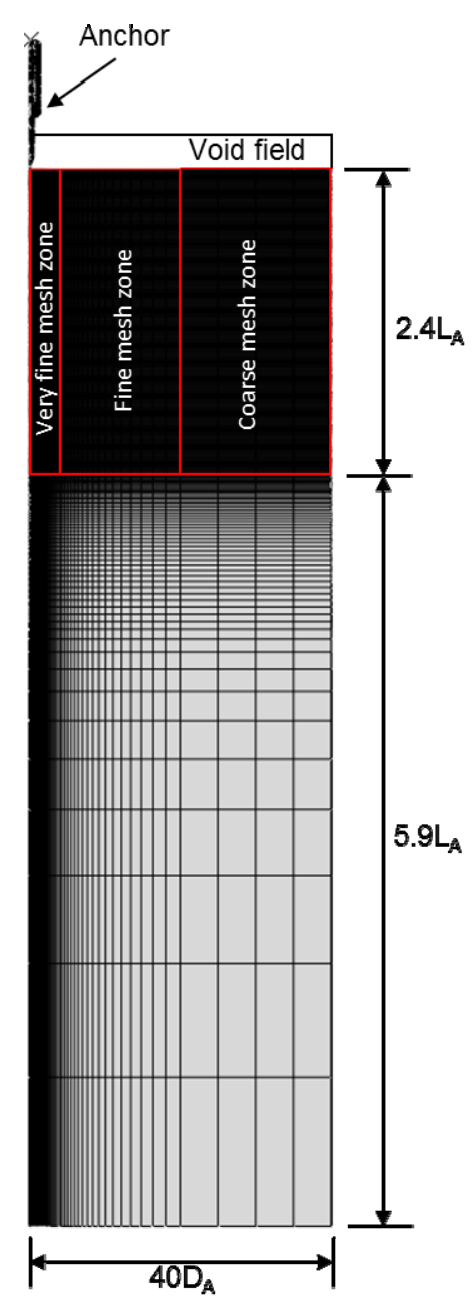

(c) Side view

Figure 2. Typical mesh used in CEL analysis 
Time, $\mathrm{t}(\mathrm{sec})$

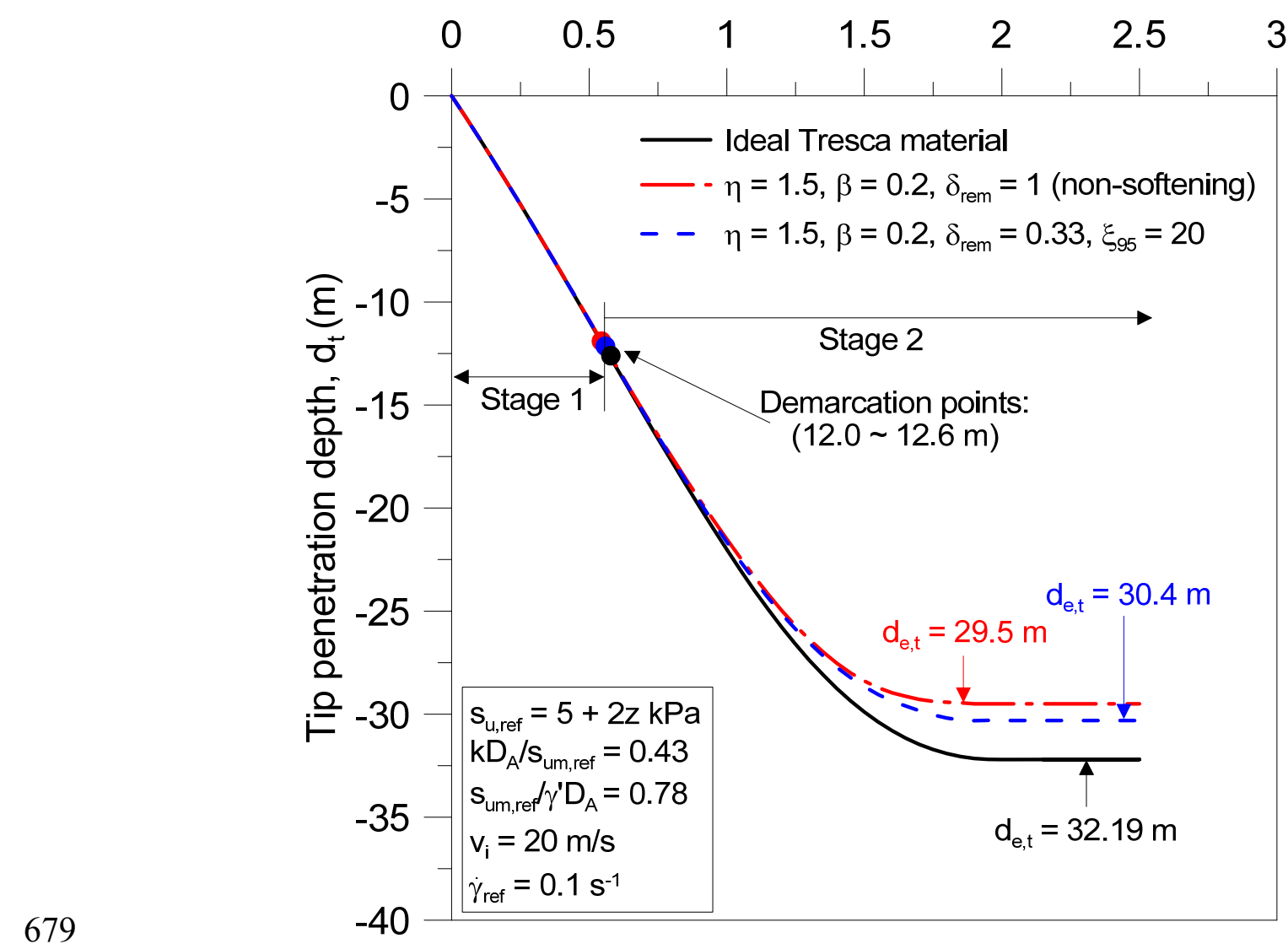

680

3(a) Embedment depths

681

682

683 


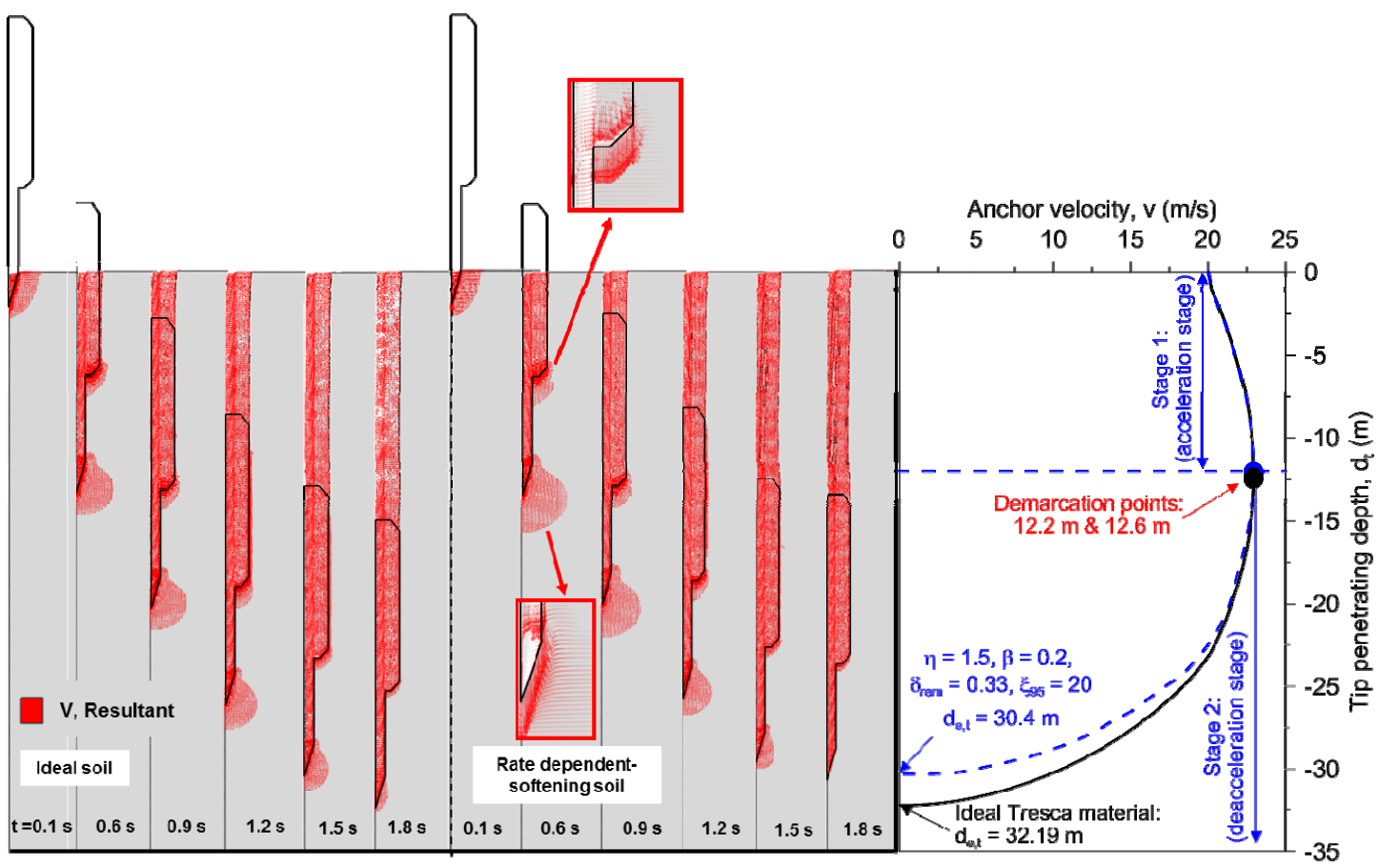



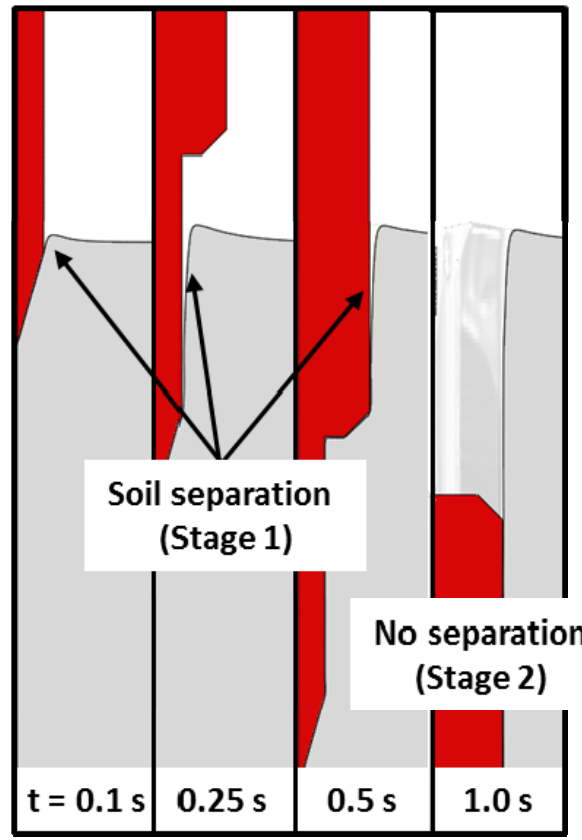

3(c) Soil separation at shallow depth

690

Figure 3. Effect of strain rate and strain softening on embedment depths and soil failure 693 
694

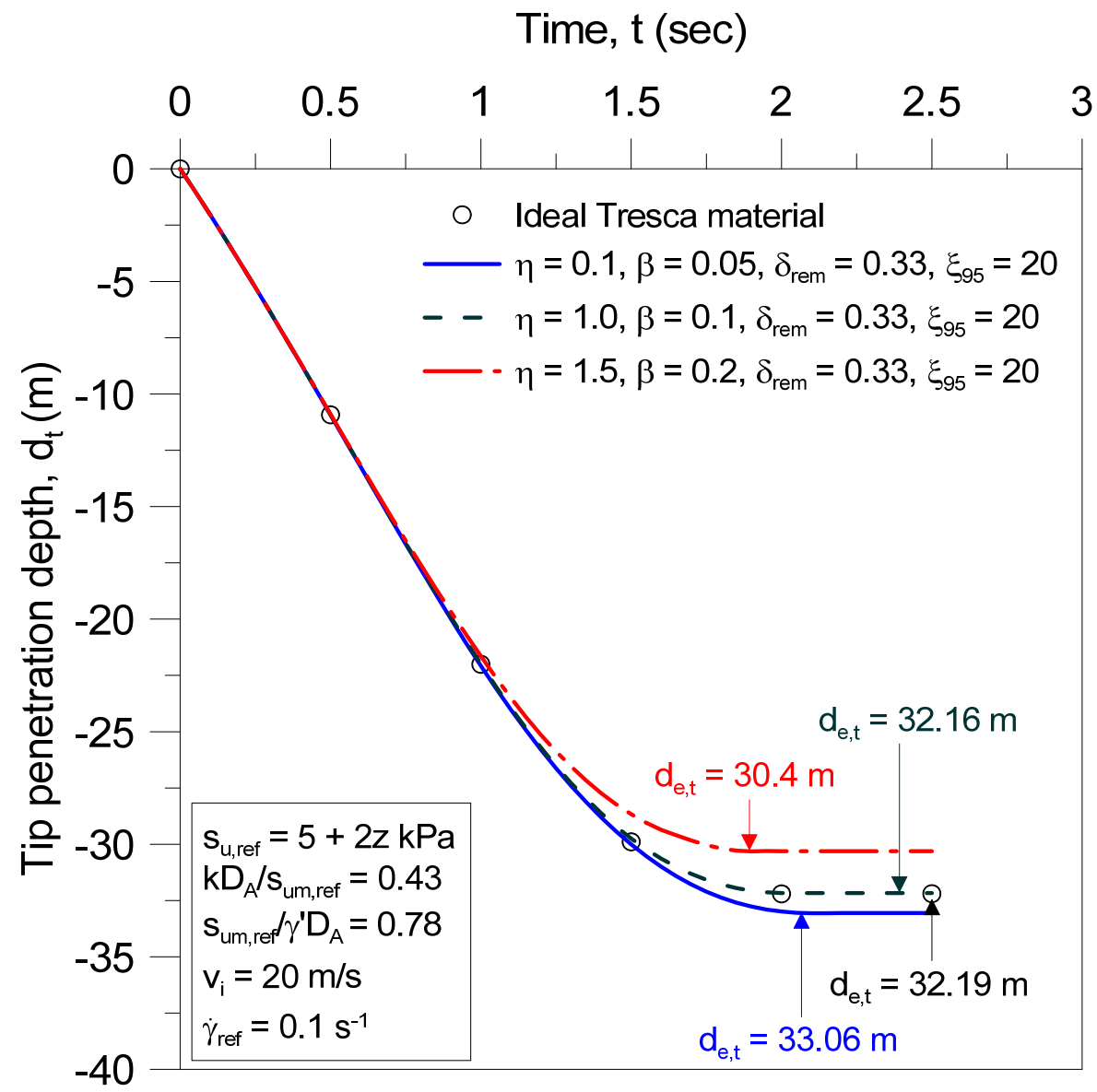

696

697

698

Figure 4. Effect of strain softening parameters $\eta$ and $\beta$ on anchor embedment

699

700

701 
Time, $\mathrm{t}$ (sec)

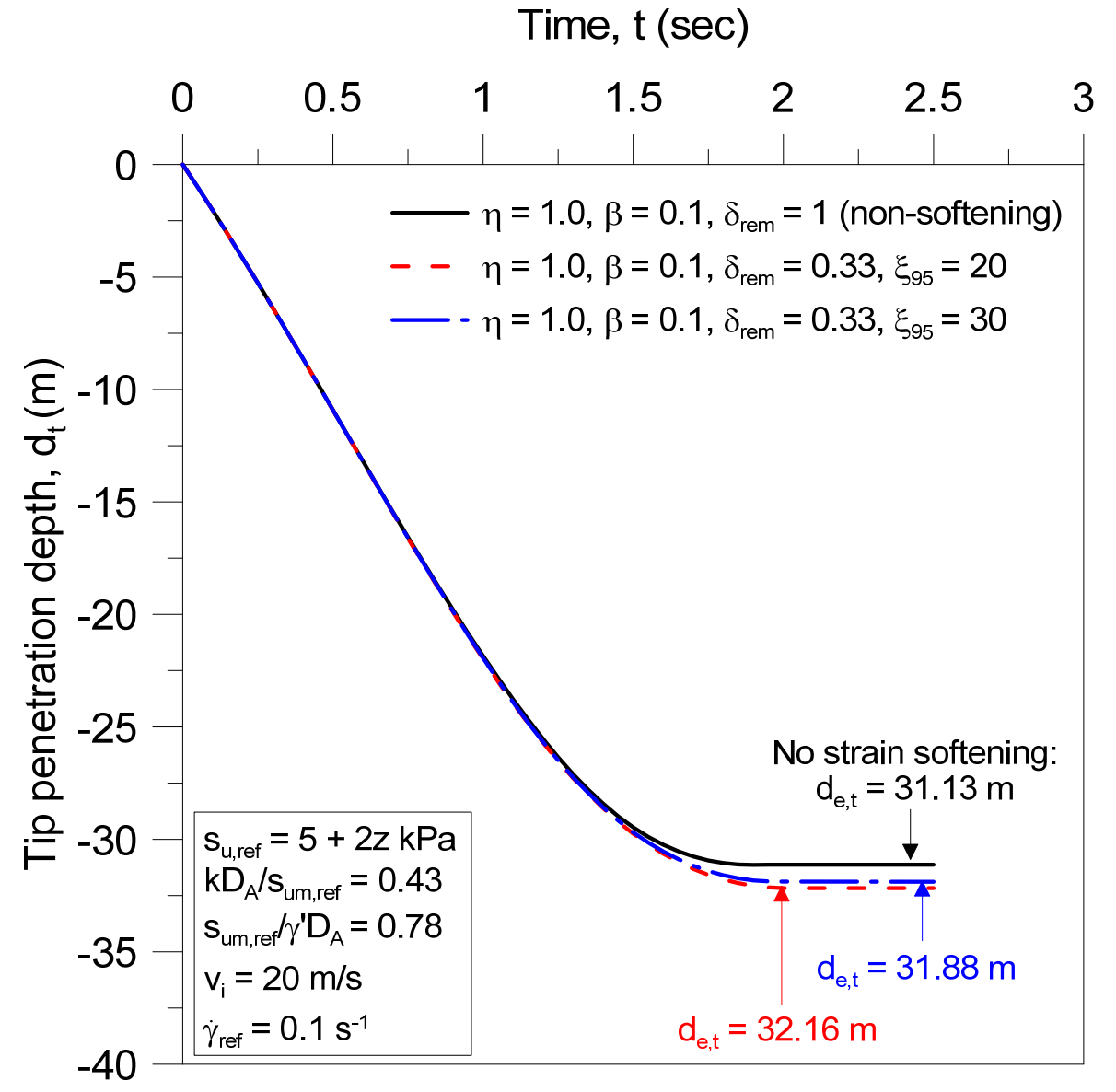

703

704

Figure 5. Effect of strain softening parameter $\xi_{95}$ on anchor embedment depth 


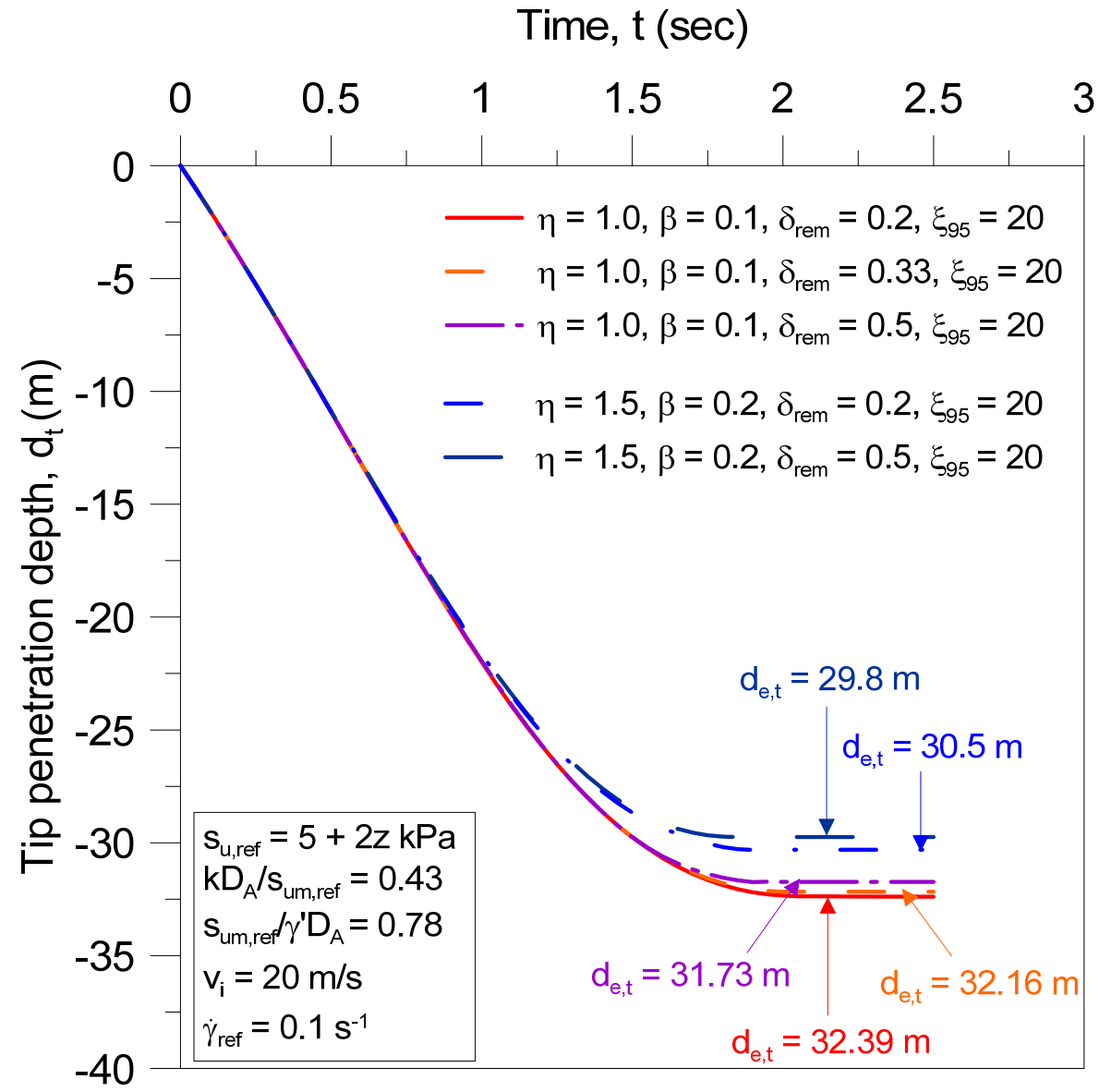

708

Figure 6. Effect of remoulded strength ratio $\delta_{\text {rem }}$ and soil sensitivity $S_{t}$ on anchor 


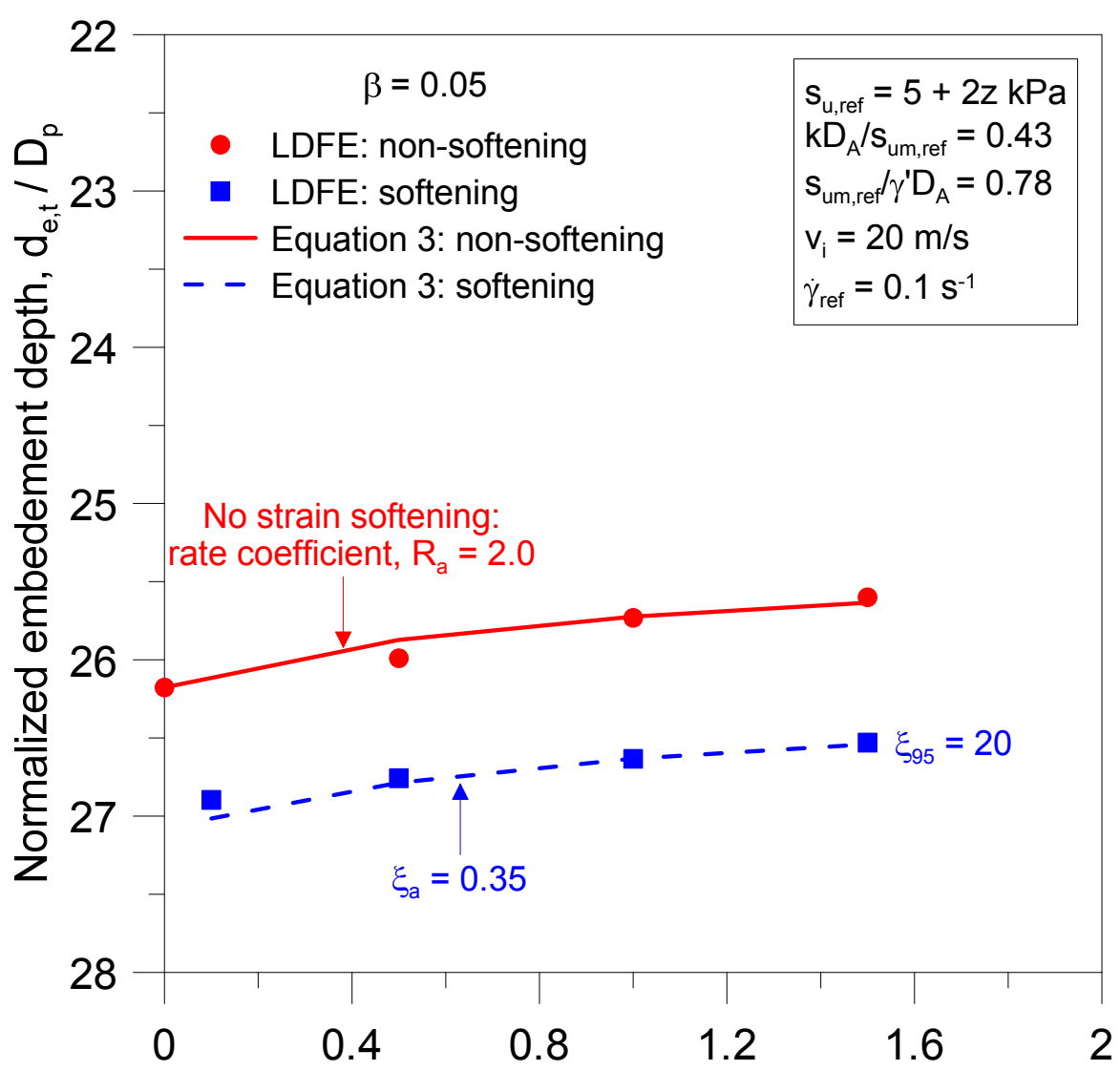

712

Viscous property, $\eta$

713

7(a) $\beta=0.05$

714 


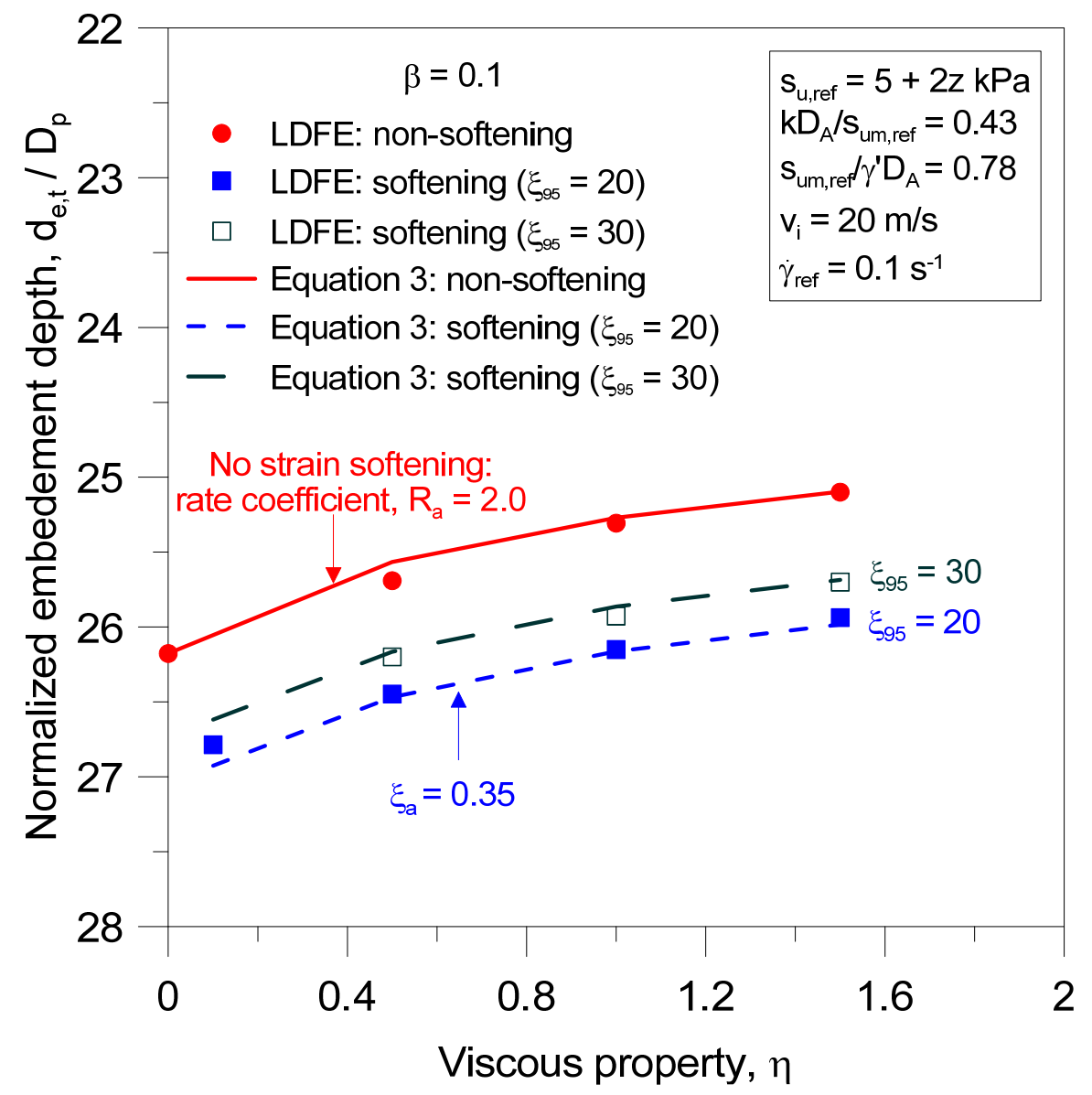

716

7(b) $\beta=0.1$ 


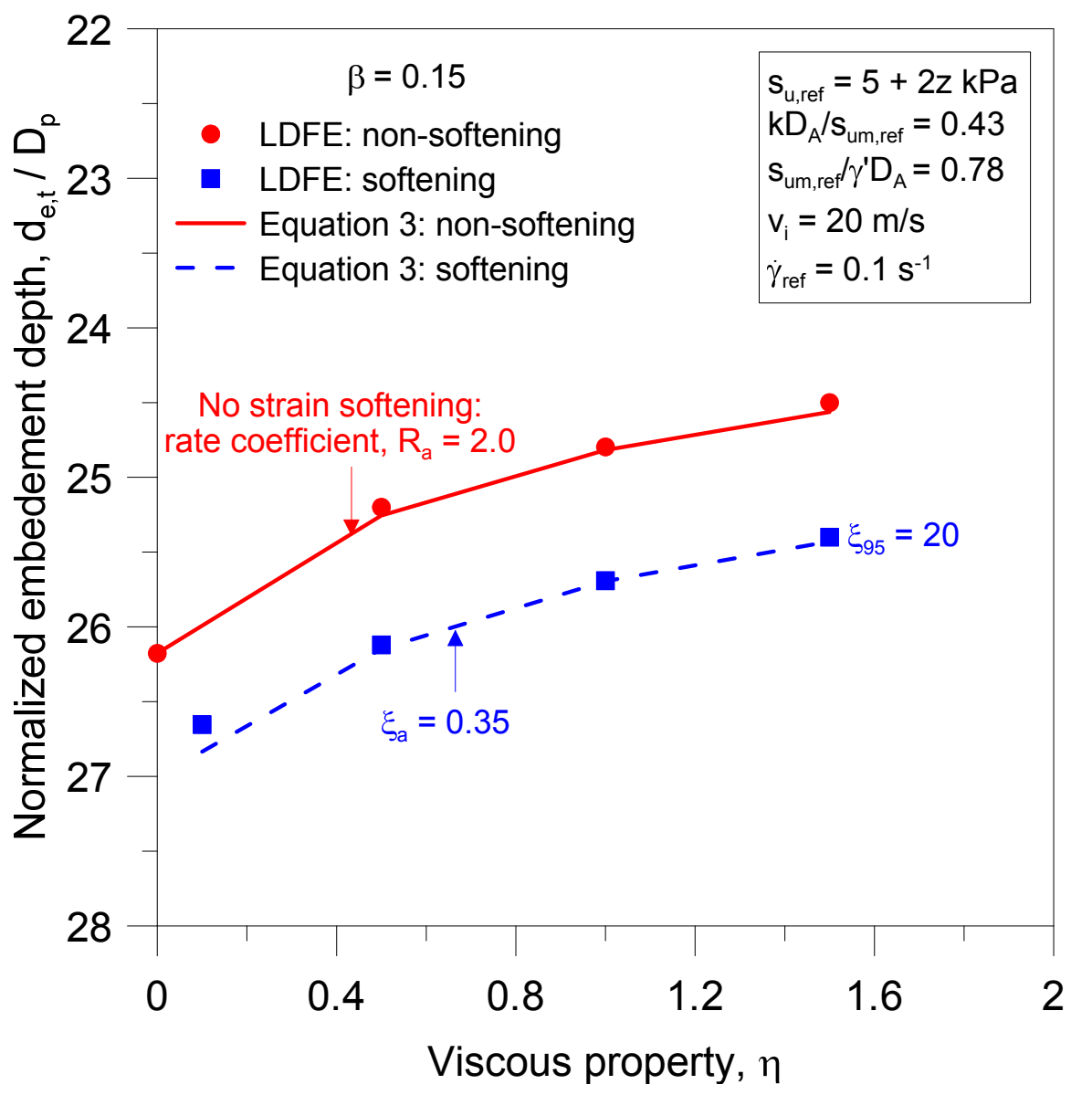

718

7(c) $\beta=0.15$ 


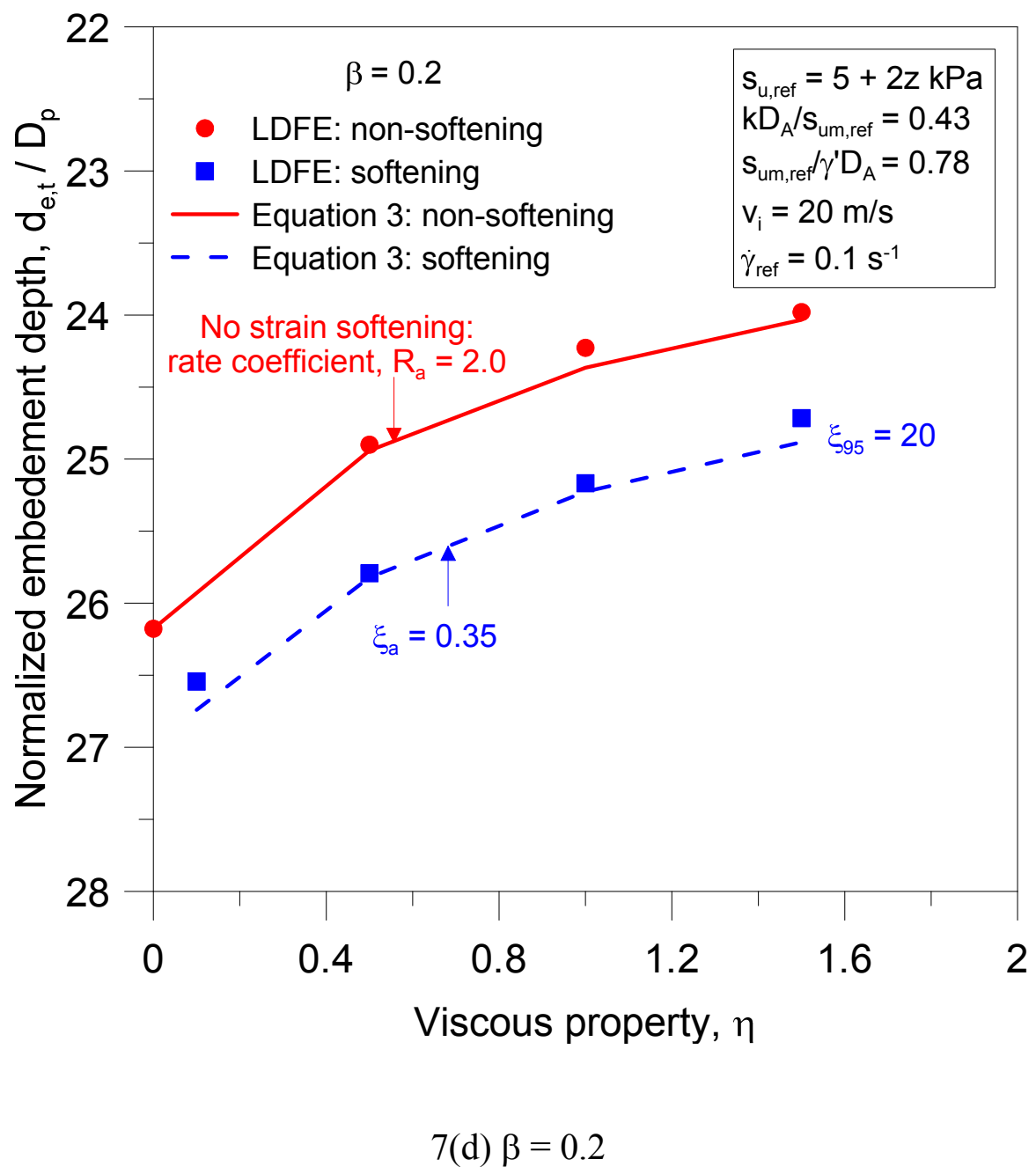

723 Figure 7. Combined effect of strain rate parameter $\eta, \beta$ and strain softening parameter $\xi_{95}$ on anchor embedment depth 
Time, $\mathrm{t}(\mathrm{sec})$

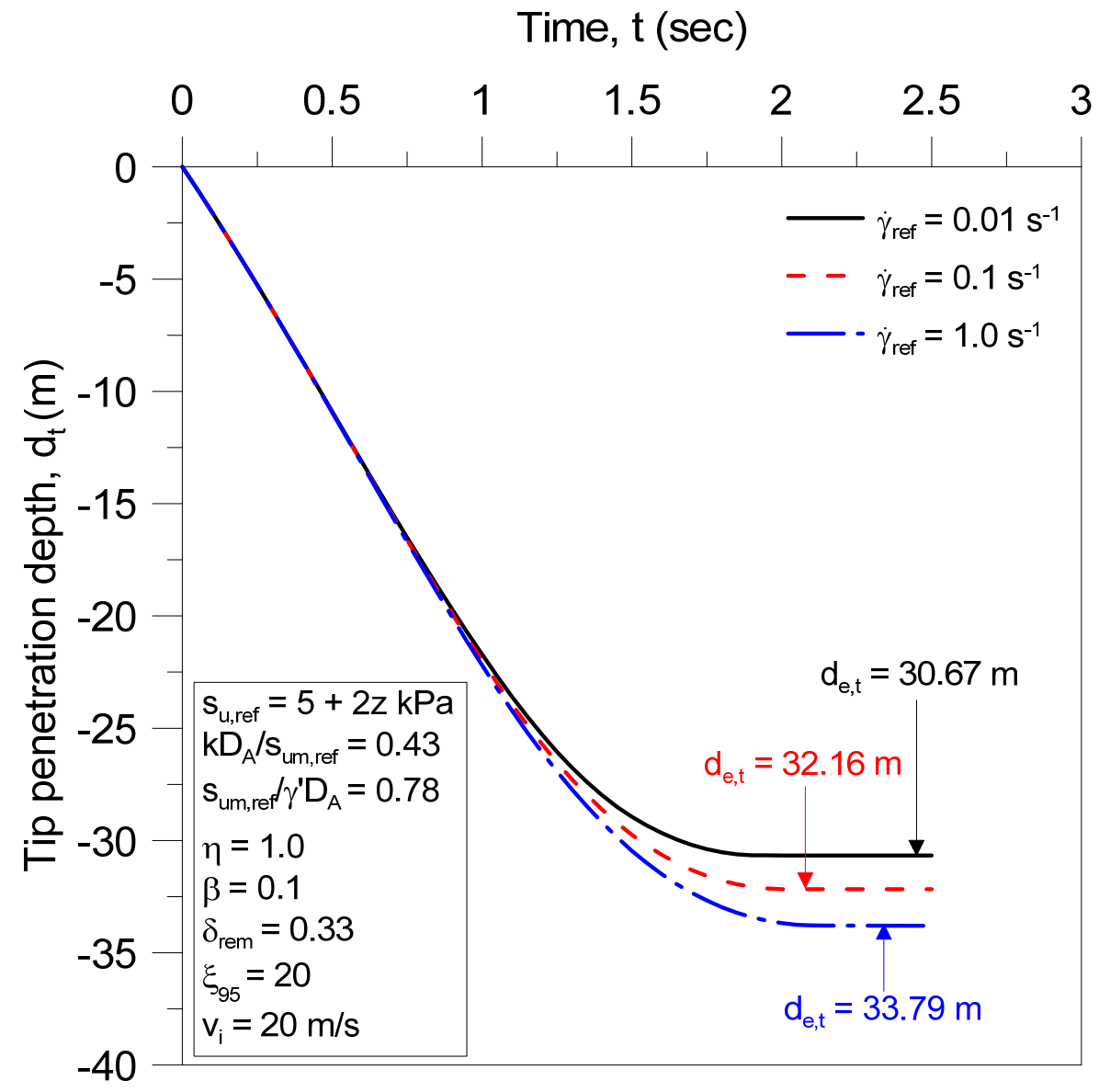

726 
Time, $\mathrm{t}$ (sec)

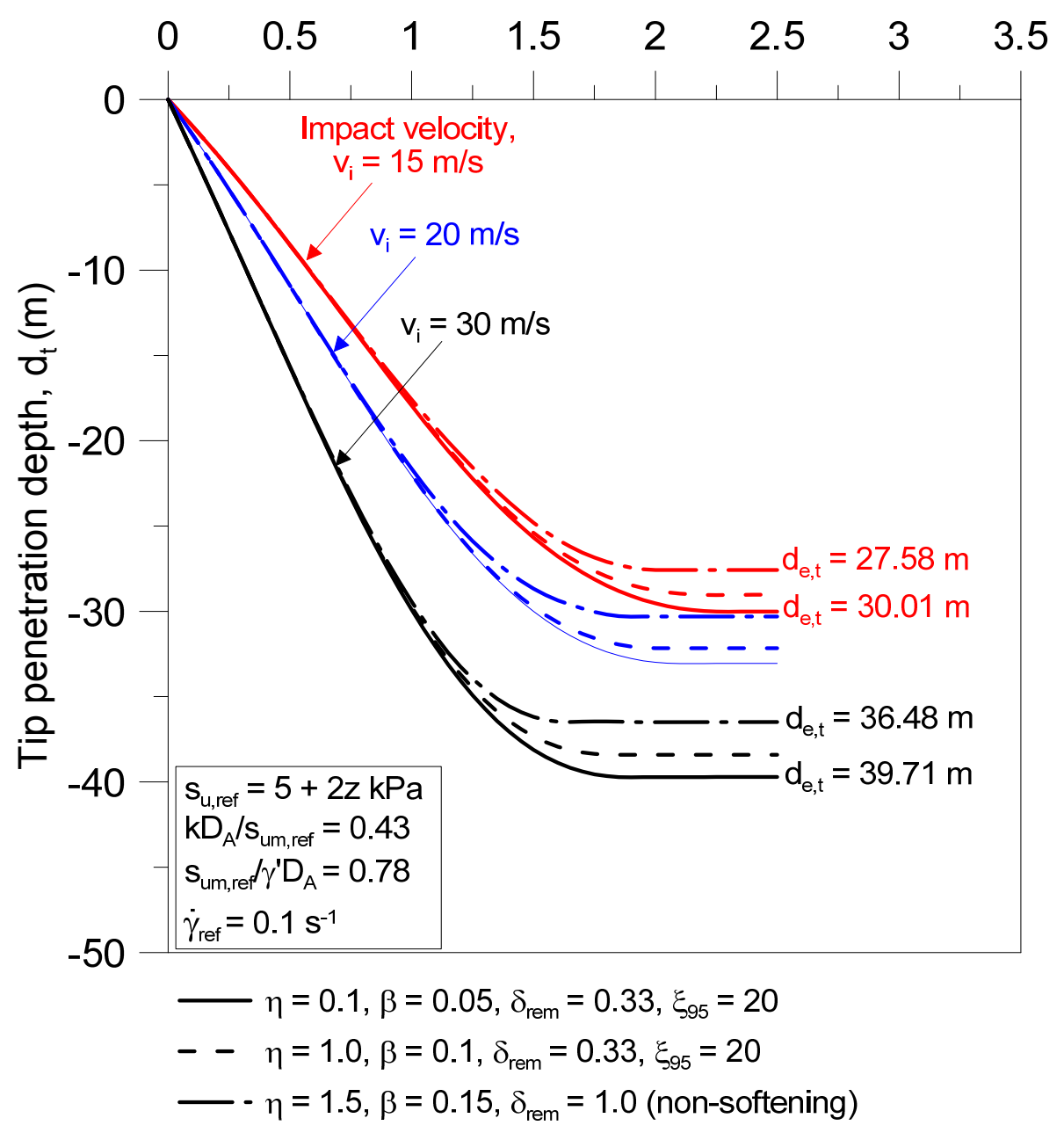




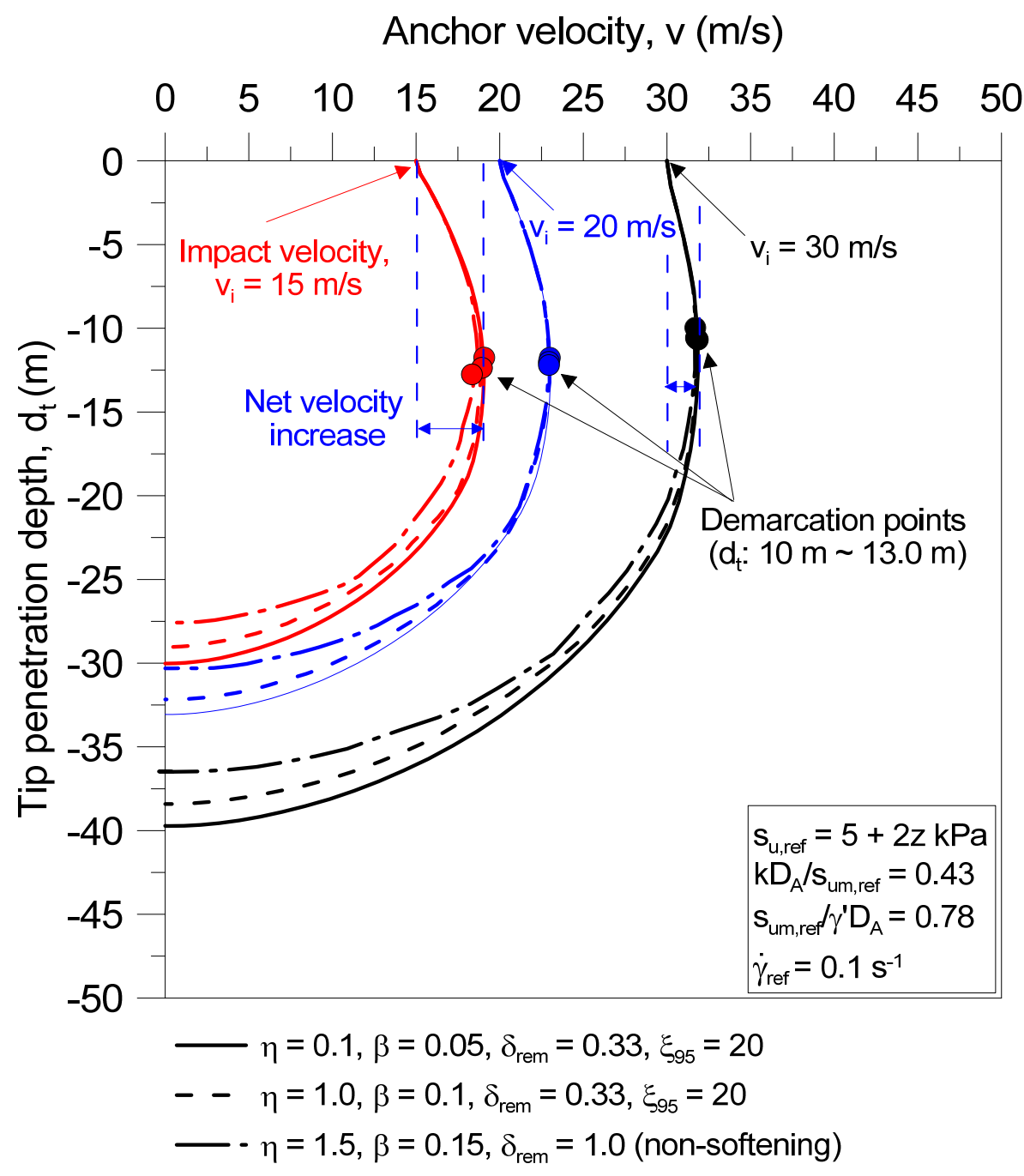




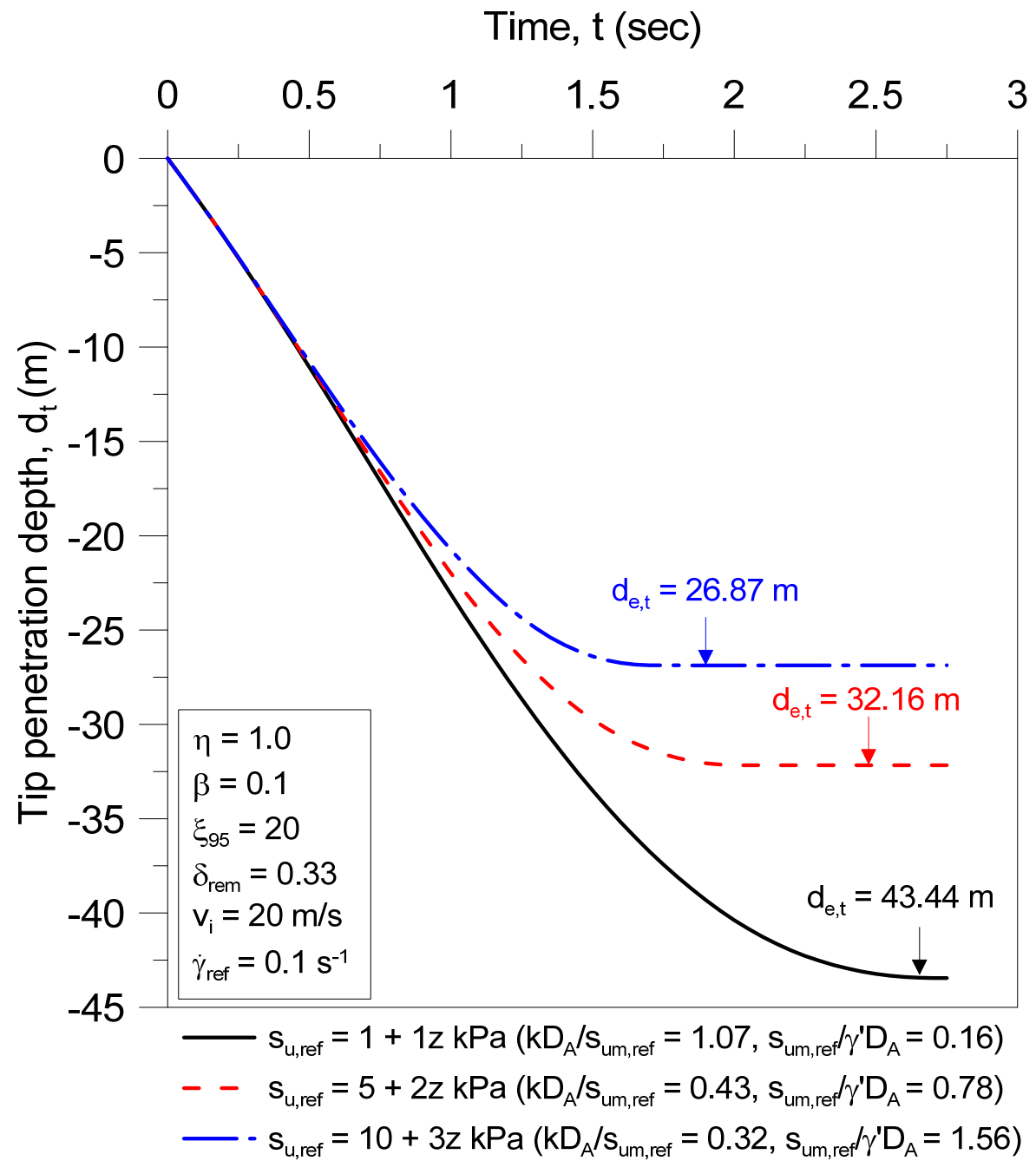

737 


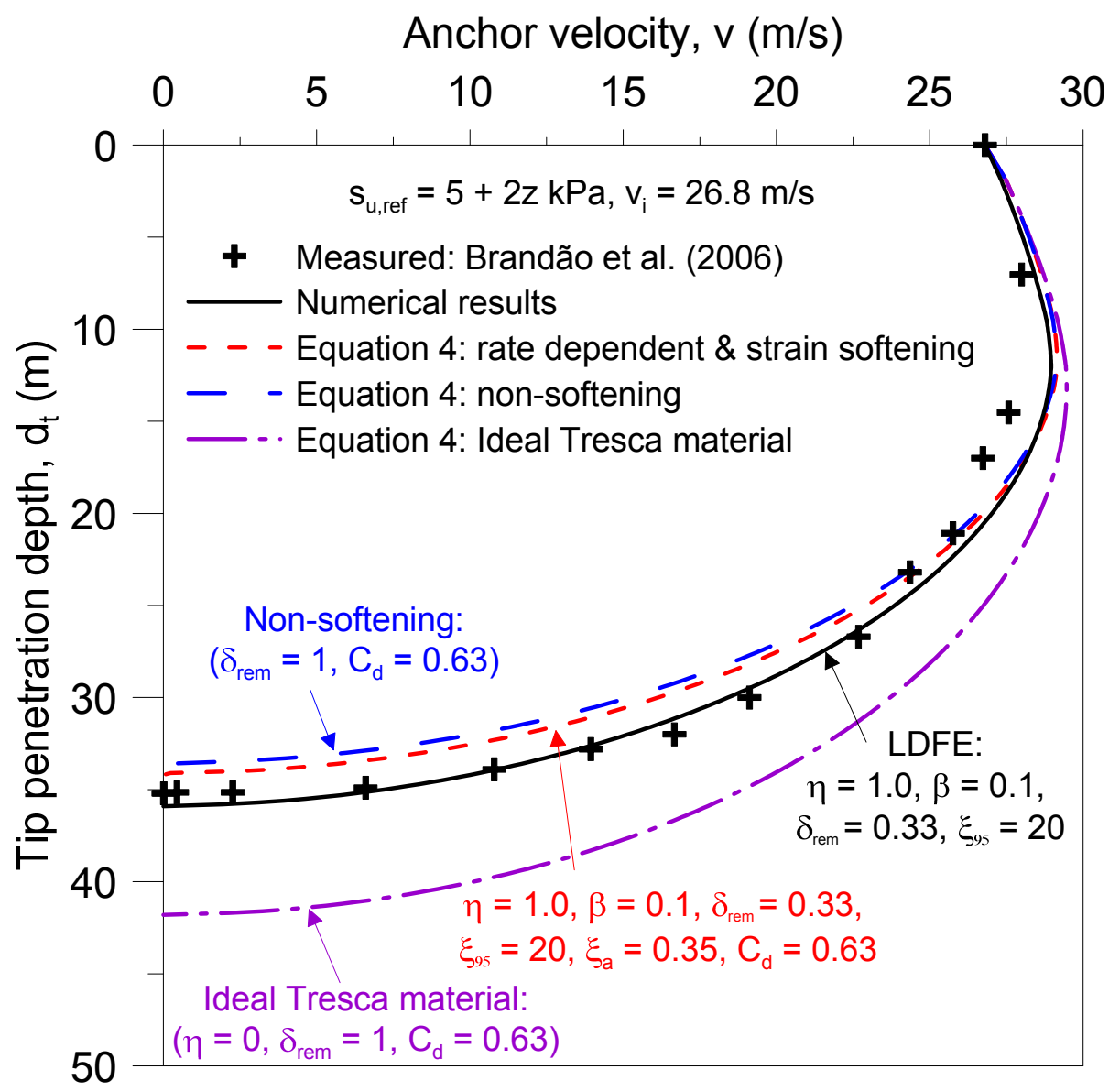




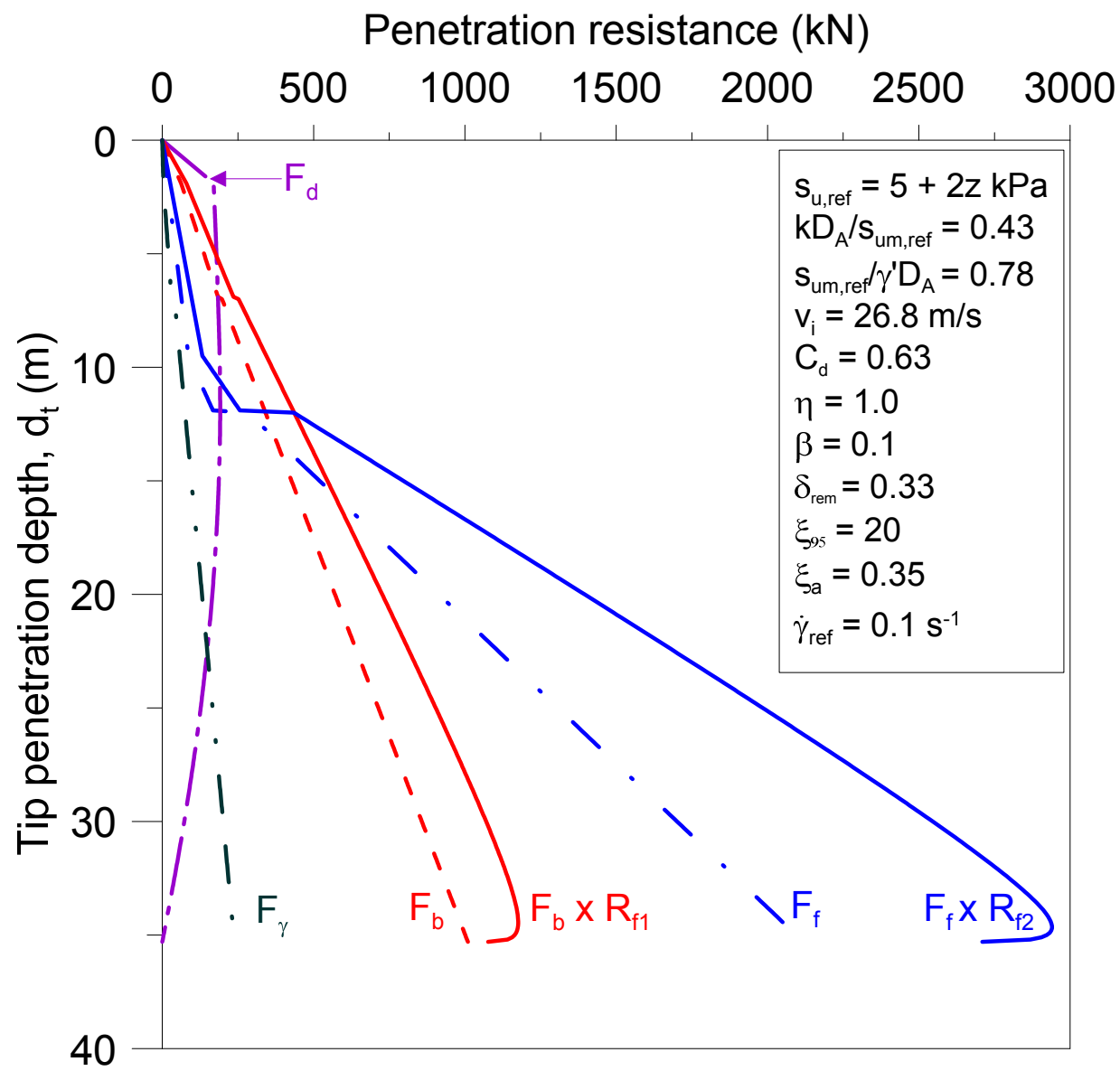

746 11(b) Contribution of various resistance force components (Equation 4: rate dependent \& strain softening) 


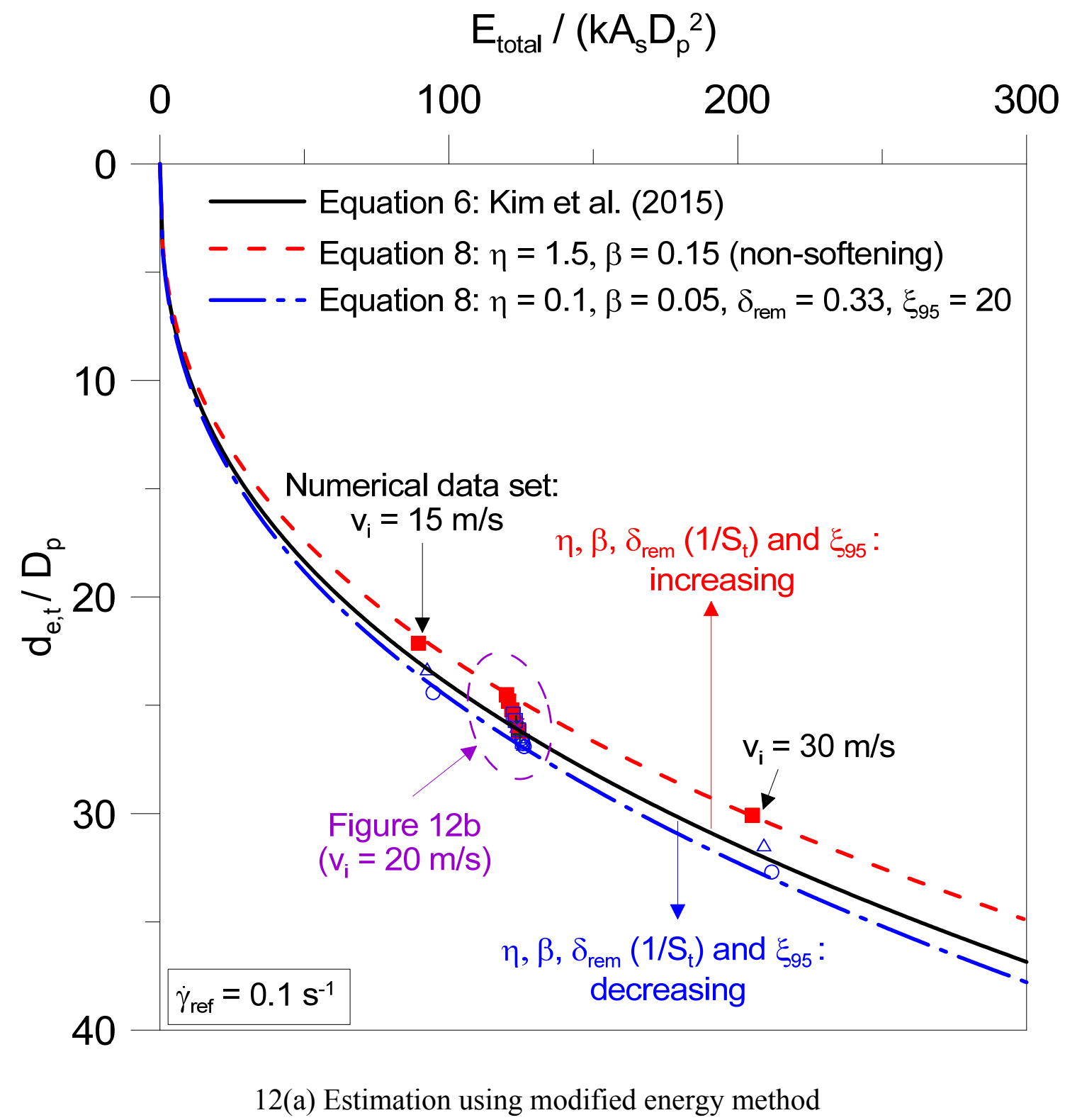




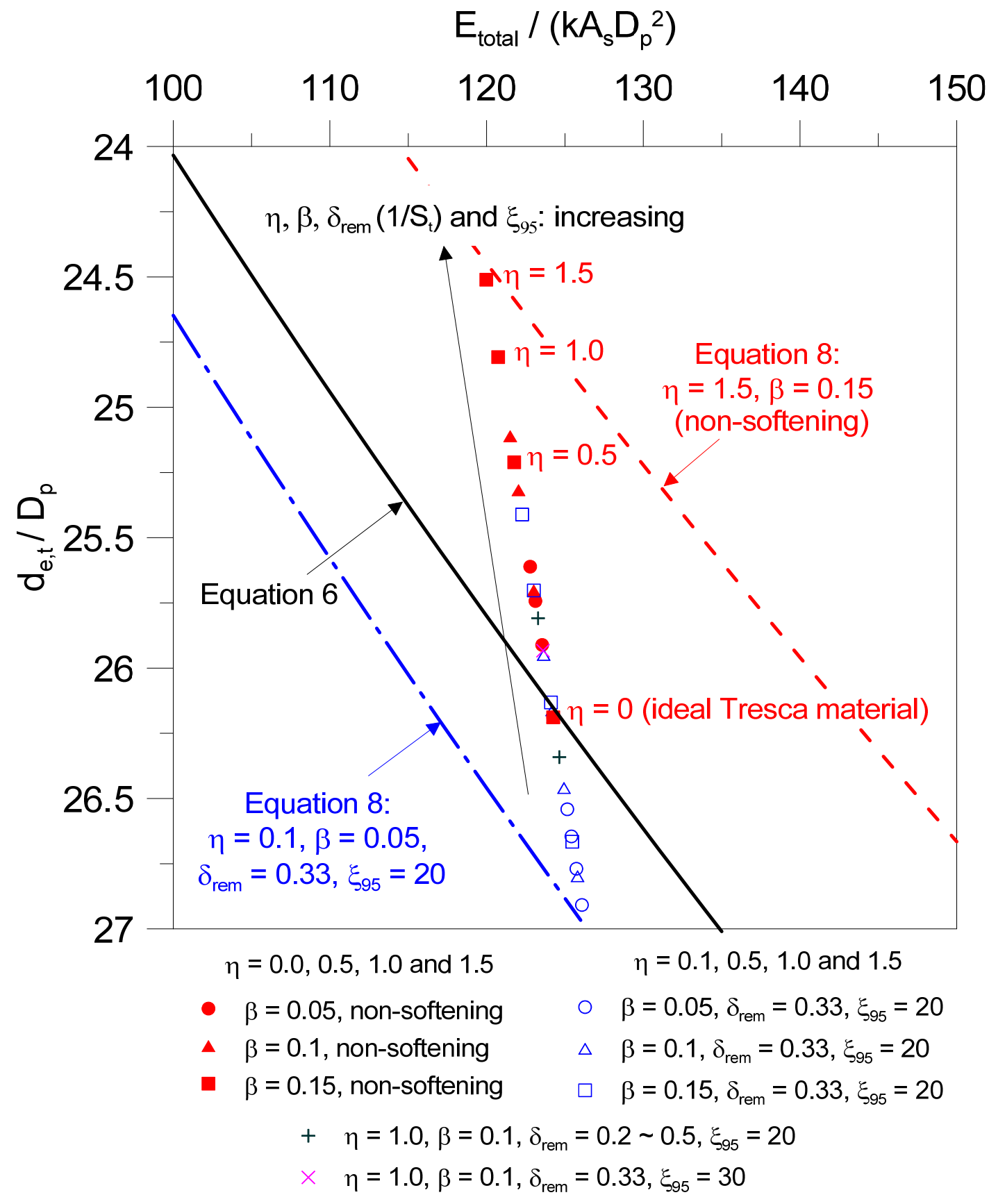

12(b) Magnification of numerical dataset 